\title{
Aspects Regarding Radiation Crosslinking of Elastomers
}

\author{
Elena Manaila, Maria Daniela Stelescu and Gabriela Craciun
}

Additional information is available at the end of the chapter

http://dx.doi.org/10.5772/47747

\section{Introduction}

Elastomers or rubbers are materials used in a large range of industrial and household applications. A common physical-chemical treatment is curing (crosslinking), imparting the rubber mechanical and thermal stability. Elastomers show low thermal conductivity values, and therefore, require complex and high cost heating methods; thus, the ionizing (accelerated electrons) method shows high interest for the grafting and crosslinking processes. In addition to the lack of environmental impact, reliability, flexibility and low costs render the radiation technologies especially attractive.

Vulcanisation is the process by which rubber is changed from essentially a plastic material to either an elastic or a hard material (Stelescu et al., 2010). In this process, an elastomer is transformed from a 'plastic', 'formable' material into an 'elastic' material by the formation of a three-dimensional network with different types of junctions. The word vulcanisation derives from Vulcan, the Roman God of fire. Not accidentally, it also means volcano, a hot place where quite some sulphur species can be found. The term vulcanisation was therefore originally exclusively applied to the crosslinking reaction achieved by sulphur at high temperatures.

Nowadays this term is also applied to refer to other crosslinking processes, such as peroxide cure. There are several possibilities for the crosslinking of rubber. The already mentioned sulphur vulcanisation was the first to be discovered and still is today's most common cure system. The sulphur vulcanisation process requires the presence of carbon-carbon unsaturation in the polymer and it leads to a three-dimensional rubber network in which the polymer chains are linked to each other by sulphur bridges. As a result, sulphur cured articles have good tensile and tear strength, good dynamic properties, but poor high temperature properties like ageing, for instance (Alvarez Grima, 2007; Dluzneski, 2001). 
Other vulcanisation systems, i.e. peroxides, ultraviolet light, electron beam, microwave, resins, etc. were later discovered and gained more importance with the progressive development of synthetic rubbers.

The use of organic peroxides as crosslinking agents for rubber was first reported by Ostromislenski in 1915 (Alvarez Grima, 2007) and at present it is the only vulcanization method that can compete with accelerated sulphur cure, with respect to vulcanization rate. Interest in the industrial use of peroxides as curing agents increased with the introduction of a number of fully saturated elastomers, such as ethylene-propylene rubber (EPM), fluoro elastomers (FKM), etc., which cannot be cured by sulphur vulcanization (Alvarez Grima, 2007). Peroxide vulcanisation leads to a rubber network in which the polymer chains are linked to each other by very stable covalent carbon-carbon bonds. Peroxide cured vulcanisates have therefore good high temperature properties, like heat ageing and compression set, compared to sulphur cured articles (Alvarez Grima, 2007; Dluzneski, 2001)

In addition, peroxide cure allows vulcanisation of both unsaturated and saturated polymers, which is not possible with sulphur vulcanisation. On the other hand, some mechanical properties of peroxide cured articles are inferior to those achieved by sulphur cure, i.e. tensile strength, dynamic properties, and therefore entail a limitation on the use of this vulcanization system. Another serious problem with peroxides is the lack of sufficient scorch time. Scorch time: the time elapsed until vulcanisation starts, is of major importance in order to control the vulcanisation reaction. The term scorch safety refers to a certain scorch time which is enough to provide good processing of the material before it starts vulcanising; this is of great importance especially in industry. Upon reaching the typical dissociation temperature of a peroxide, the crosslinking reaction immediately proceeds at full speed, leaving the processor little or no time for shaping of the rubber article. The addition of certain scorch-retarders is sometimes of help, but this usually goes at the expense of crosslink density obtained: a waste of money (Alvarez Grima, 2007).

\section{Electron beam and microwaves vulcanization}

Radiation curing has historically been used as an alternative to peroxides in applications where the curatives themselves or sideproducts of vulcanization are viewed as impurities in the final product. Peroxide cure progresses through a series of radical intermediates, each of which can undergo side reactions which may not necessarily contribute to crosslink density. Radiation cure, on the other hand, has been promoted as a cleaner and more homogeneous cure process. Electron beam irradiation has been used in the wire and cable industry for longer than 30 years and applied to a wide range of commodity and specialty elastomers. A survey of the types of elastomers susceptible to radiation curing is available, as are review articles describing the electron-beam curing of commercially significant grades (Bhowmick \& Vijayabaskar, 2006; Henning, 2008). Variables such as radiation dosage and the effect of polymer microstructure and chemical additives on the efficiency of electron beam cure have been studied. Some researchers (Zaharescu et al., 2000; Chowdhury \& Banerji, 2005) studied radiation-induced crosslinking in thermoplastic elastomers based on ethylene-propylene rubber (EPDM) and polyethylene (PE) or polypropylene (PP) plastics. 
Elastomer crosslinking by means of electron beam (EB) is done without heating and in the absence of vulcanization agents. The reaction mechanism is similar to crosslinking with peroxides, but in this case, reaction initiation is due to the action of EB and in the presence of the polyfunctional monomers. Ionizing radiation produces an excitation of polymer molecules. The energies associated with the excitation are dependent on the irradiation dosage of electrons. The interaction results in formation of free radicals formed by dissociation of molecules in the excited state or by interaction of molecular ions. The free radicals or molecular ions can react by connecting the polymer chains directly or initiating grafting reactions.

EB vulcanization has demonstrated extremely positive results compared to the conventional curing system such as: no polymer degradation due to high temperature as EB crosslinking occurs at room temperature, no oxidative degeneration in polymers as observed in classical crosslinking, direct crosslinking by C-C linkage by EB, extremely strong bonds, high degree of crosslinking, extremely short curing cycles, zero blooming effects; extremely high tensile strength; extremely high resistance to compression set; extremely high resistance to oils, grease, lubricants; highly improved accelerated ageing properties, very high productivity, perfect for thin products, lower material waste (MGM Rubber Company-Research and Development, 2007). However, the radiation crosslinking of rubbers was not used in larger technical applications because of the high cost of irradiation to bring about vulcanization, but could become an industrial process when the radiation dose decreased with the use of some sensitizers.

Modification of thermoplastic and rubbery materials by EB and microwave (MW) radiations is a potential method for the development of new materials like polymers and composites. Interaction of each of the two physical systems, EB and MW, with a substance has revealed their ability for changing physical and chemical proprieties of the treated substance.

Therefore, the physical and chemical effects of the EB and MW radiation have drawn high interest, resulting in a large industrial application range of the new materials with improved characteristics. A comparative study of the effects of separate interaction of EB and MW with the substance, effects on which the modern processes for the production of new materials with special characteristics have been developed, has revealed the following: (a) production of materials by EB (ionizing) radiation is based on the coulomb interaction of accelerated electrons with the atoms of the substances they are penetrating. From this interaction, secondary electrons, excited molecules, free ions and radicals result, which are precursors of some chemical reactions resulting in new materials; (b) production of materials by MW (non-ionizing) radiation is based on thermal effects (dielectric heating) of the interaction of the electromagnetic waves with the substance. MW energy absorbed within the substance is dependent on the molecule characteristics, that is on the permittivity and magnetic permeability resulting in a high selectivity level for the chemical reactions induced by MW interaction with the constituents of the material they are penetrating; (c) by separate/ combined EB and MW irradiation, materials with single characteristics are obtained with high yields, inaccessible by the traditional curing methods.

Radiation (EB-ionizing radiation and MWs-non-ionizing radiation) are used successfully instead of the traditional methods and, in addition, provides new possibilities like as 
crosslinking in thick polymer articles, in complex sections or production of recycled rubbers of high quality.

The high-molecular compounds (elastomers) are made up of a large number of elementary molecules - monomers. These molecules can be of the same class or of different classes, resulting thus homopolymers and copolymers, respectively. The radiation acts on the highmolecular compounds as follows: (1) at a relatively low radiation dose (radiation dose $=$ the energy absorbed per unit of mass of the irradiated material; it is measured in $\mathrm{J} / \mathrm{Kg}$; unit of measure for the absorbed dose is a gray: $1 \mathrm{~Gy}=1 \mathrm{~J} / \mathrm{kg}$ ), only "pure polymerization" occurs. With the linear increase in the radiation dose, the linear polymer chains increase progressively by addition of a molecule from a blend with low molecular weight to a radical at the end of an increasing chain; (2) with the dose increase during the pure polymerization, a new process named "grafting" takes place. By this process side chains are made in the polymer, resulting in modified surface properties in some materials, like as: biocompatibility, moisture-absorbent and moisture-repellent, and mechanical, chemical and thermal characteristics. This process is very promising for the biomaterial synthesis. (3) with the further increase in radiation dose, the "crosslinking" process takes place, when links are formed between polymer chains resulting in two- and three-dimensional structures. During this process insignificant chemical changes occur but significant structural changes. Simultaneously degradation occurs. Crosslinking and degradation (through chain scission) are two competing processes that always co-exist under radiation. Both processes have many applications in the field of new materials with improved characteristics, like as elastomer crosslinking. (4) the combined effects of the two processes are used in many industry processes, being known as „radiation curing". Three radiation induced processes are used in "radiation curing": monomer polymerization, polymer chain crosslinking and chemical bonding between polymer and substrate molecules.

Use of ionizing and non-ionizing radiation to obtain materials with improved characteristics is based on their advantages like as: (I) electrons beam (EB): (I.1.) accelerate the polymerization/vulcanization process, thus reducing the preparation time with tens to hundreds times; (I.2.) increase the conversion of raw material into the finished material up to a $100 \%$ yield and, therefore, the percentage of the residual monomer is nearly $0 \%$, which is very important with noxious monomers; (I.3.) reduce the energy required in crosslinking and grafting with 5-10 times as compared with the traditional method; (II) microwaves $(M W)$ : (II.1.) promote a narrow distribution of the molecular masses, as the crosslinking and grafting occurs simultaneously in the bulk due to the rapid energy transfer, volumetric and selective properties of MW dielectric heating, (II.2.) promote fast crosslinking and grafting processes, by tens to hundreds times faster than in classical procedure because the electromagnetic energy is directly transferred from the MW to the atoms or molecules of the irradiated material

\section{Polyfunctional monomers (co-agents)}

Reported papers suggest that appropriate polyfunctional monomers (co-agents) in polymer matrix (Vijayabaskar \& Bhowmick, 2005; Yasin et al., 2005) could be used to obtain desired 
rubber physical properties at lower irradiation doses (Hafezi et al., 2006; Stelescu et.al., 2011; Stelescu et al., 2012). Co-agents are multi-functional organic molecules which are highly reactive towards free radicals (Alvarez Grima, 2007). They are used as reactive additives to boost the vulcanization efficiency (Endstra, 1990). The most used coagents are molecules with maleimide groups, (meth)acrylate groups, or allylic groups, (Dikland et al., 1993) but polymeric materials with a high vinyl content, i.e. 1,2-polybutadiene, can also act as coagents.

The co-agents can be divided into two groups: Type I and Type II co-agents.

Type I: Addition and hydrogen abstraction reactions: these co-agents consist of rather polar molecules with a low molecular weight and activated double bonds. Their main characteristic is that they are highly reactive towards radicals, so scorch takes place very fast, which sometimes can be a disadvantage. By using this kind of coagents not only the rate of cure is increased but also the crosslink density or state of cure. A disadvantage that may be present when using this type of co-agents is that, due to polarity, the compatibility of these co-agents with the polymer matrix is limited. Some examples of Type I co-agents are: acrylates, methacrylates, bismaleimides and zinc salts.

Type II: Addition reactions: these co-agents are, in general, less polar molecules, which form more stable free radicals, so scorch does not take place as fast as with the previous type of co-agents. The use of these co-agents leads to an increase in crosslink density of the vulcanisate but, unlike Type I, they are not capable of increasing the cure rate. Due to their low polarity, these co-agents have a good compatibility with many elastomers. Some examples are: high-vinyl 1,2-polybutadiene, divinylbenzene, allyl esters of cyanurates, isocyanurates and sulphur.

This review gives an overview about our research (Stelescu \& Manaila, 2007; Zuga et al., 2007; Zuga, Miu et al., 2007; Manaila et al., 2008; Stelescu et al., 2010; Manaila, Martin, Stelescu et al., 2009; Stelescu et al., 2009; Manaila, Martin, Craciun et al., 2009; Stelescu et al., 2008; Manaila, Stelescu, Ighigeanu et al., 2011; Manaila, Stelescu et al., 2011) on elastomer crosslinking by irradiation with accelerated electrons, a much more ecologic method that does not need to add crosslinking agents into the blend.

In addition, the main advantages that the new technique brings are: (a) almost 100\% efficiency in converting raw material into finished materials; (b) reduction from tens to hundreds of times of the production length; (c) achieving unique properties of materials which cannot be obtained by conventional methods; (d) perfect adaptability to the highest demands on the environment because no reaction by-products are released into the atmosphere; (e) adaptability to any degree of automation (allows technological lines with speeds of over $500 \mathrm{~m} / \mathrm{min}$ ) and strict control of technological processes; (f) in many cases, reduction of energy consumption by 20 to 30 times compared to "classic heating" or conventional processes; ( $\mathrm{g}$ ) the process is simple and can be controlled by only one single parameter, i.e. absorbed dose, the quantity that varies with the application; (h) radiation crosslinking is technically and economically feasible as a pure physical process, i.e. without 
the addition of sensitizers, there are no residues of alien substance needed for the chemical processes, or of their decomposition products.

At the interaction of ionizing radiation with (co)polymers, breaking of covalent bonds occurs, as well as the emergence of free radicals (transitional chemical species) on the main chain (if the lateral groups break) or in the main chain (if it breaks itself). The final effect is either crosslinking of macromolecular assembly or cutting the main chain of macromolecules and decreasing average molecular weight. In fact, the two effects, crosslinking and degradation, coexist and we need to point out the predominance of one of them.

In our study we used five polyfunctional monomers: TAC (triallylcyanurate) and TAIC (triallylisocyanurate) of type II, and TMPT (trimethylopropane trimethacrylate), EDMA (ethylene glycol dimethacrylate) and ZDA (zinc diacrylate) of type I.

Table 1 presents the chemical structure, type, functionality, and characteristics of polyfunctional monomers (co-agents) PFMs used.

\begin{tabular}{|c|c|c|c|}
\hline PFMs & Type & $\begin{array}{l}\text { Chemical } \\
\text { structure }\end{array}$ & Characteristics \\
\hline $\begin{array}{l}\text { Triallylcyanurate } \\
\text { Luvomaxx TAC DL } 70 \text { (TAC) }\end{array}$ & II & & $\begin{array}{l}\text { Melting point: } 26-28{ }^{\circ} \mathrm{C} ; \\
\text { Boiling point: } 149-152{ }^{\circ} \mathrm{C} ; \\
\text { Density: } 1.34 \mathrm{~g} / \mathrm{cm}^{3} ; \\
26 \% \text { percentage of ash, } \\
30 \% \text { active synthetic silica. }\end{array}$ \\
\hline $\begin{array}{l}\text { Triallylisocyanurate } \\
\text { Luvomaxx TAIC DL } \\
\text { 70C (TAIC) }\end{array}$ & II & & $\begin{array}{l}\text { Melting point: } 26-28{ }^{\circ} \mathrm{C} \\
\text { Boiling point: } 119-120^{\circ} \mathrm{C} \\
\text { Density: } 1.34 \mathrm{~g} / \mathrm{cm}^{3} ; \\
30 \% \text { active synthetic silica. }\end{array}$ \\
\hline $\begin{array}{l}\text { Trimethylolpropanetrimethacrylate } \\
\text { Luvomaxx TMPT DL } 75 \text { (TMPT) }\end{array}$ & I & & $\begin{array}{l}\text { Melting point: }-25^{\circ} \mathrm{C} ; \\
\text { Boiling point: }>200^{\circ} \mathrm{C} ; \\
\text { Density: } 1.36 \mathrm{~g} / \mathrm{cm}^{3} ; \\
22 \% \text { percentage of ash, } \\
75 \pm 3 \% \text { active ingredient. }\end{array}$ \\
\hline $\begin{array}{l}\text { Ethylene glycol dimethacrylate } \\
\text { Luvomaxx EDMA DL } 75 \text { (EDMA) }\end{array}$ & I & & $\begin{array}{l}\text { Melting point: }-40^{\circ} \mathrm{C} ; \\
\text { Boiling point: } 85^{\circ} \mathrm{C} ; \\
\text { Density: } 1.25 \mathrm{~g} / \mathrm{cm}^{3} ; \\
23 \% \text { percentage of ash, } \\
75 \pm 3 \% \text { active ingredient. }\end{array}$ \\
\hline Zinc-diacrylate ZDA GR 75 (ZDA) & I & & $\begin{array}{l}\text { Melting point: } 240-244^{\circ} \mathrm{C} \\
\text { Boiling point: } 141^{\circ} \mathrm{C} ; \\
\text { Density: } 1.23 \mathrm{~g} / \mathrm{cm}^{3} \\
75 \pm 3 \% \text { active ingredient. }\end{array}$ \\
\hline
\end{tabular}

Table 1. Characteristics of polyfunctional monomers (co-agents) PFMs used 


\section{Experimental installations, sample irradiation and laboratory tests}

The experimental installation consists mainly of the following units: an accelerated electron beam source, a microwave source of $2.45 \mathrm{GHz}$ and a multimode rectangular cavity used as reaction chamber. As accelerated electron beam source is used the electron accelerator ILU$6 \mathrm{M}$ and electron linear accelerator ALIN-10. Two experimental installations for the separate EB irradiation and combined irradiation with EB and MW are carried out: experimental installation $A$ and experimental installation $B$.

Each experimental installations consists mainly of the following units: an electron beam source, a microwave source of $2.45 \mathrm{GHz}$, a multimode rectangular cavity in which are injected both, EB and MW. Experimental installation A uses as electron beam source the electron linear accelerator ALIN-10 of $6.23 \mathrm{MeV}$ and $70 \mathrm{~Gy} \mathrm{~s}^{-1}$ maximum dose rate (built in the NILPR Institute, Bucharest, Romania). Experimental installation B uses as electron beam source the industrial electron accelerator ILU-6M of $1.8 \mathrm{MeV}$ and $10.8 \mathrm{~kW}$ maximum output power, built in Russia, Institute of Nuclear Physics-Novosibirsk. It is placed at Electrical Project and Research Institute from Bucharest, Romania.

The ALIN-10 electron accelerator was built in Romania, National Institute for Lasers, Plasma and Radiation Physics, Electron Accelerator Laboratory-Bucharest, is of the travelling-wave type, driven by 2-MW peak power tunable EEV M5125-type magnetrons operating in Sband The optimum values of the EB peak current Iвв and EB energy Евв to produce maximum output power РЕв for a fixed pulse duration $\tau_{\mathrm{EB}}$ and repetition frequency fЕв are as follows: $\mathrm{E}_{\mathrm{EB}}=6.23 \mathrm{MeV}$; Ieb $=75 \mathrm{~mA}$; $\mathrm{P}_{\mathrm{EB}}=164 \mathrm{~W}$ (feB $\left.=100 \mathrm{~Hz}, \tau_{\mathrm{EB}}=3.5 \mu \mathrm{s}\right)$. The main characteristics of the ALIN-10 electron accelerator are presented in Table 2.

\begin{tabular}{|c|c|}
\hline Characteristic & Value \\
\hline EA energy & $6.23 \mathrm{MeV}$ \\
\hline EA power in impulse & $75 \mathrm{~mA}$ \\
\hline EA impulse duration & $\tau=3.5 \mu \mathrm{s}$ \\
\hline EA impulse repeat frequency & $\mathrm{f}_{\mathrm{r}}=50-100 \mathrm{~Hz}$ \\
\hline Mean power & $13 \mu \mathrm{A}$ at $50 \mathrm{~Hz}$ \\
\hline Maximum mean power & $82 \mathrm{~W}$ \\
\hline
\end{tabular}

Table 2. The main characteristics of electron accelerator ALIN-10

The ILU-6M accelerated electron beam source is placed at Electrical Project and Research Institute from Bucharest, Romania. The ILU-6M is a resonator-type accelerator, operating at $115 \pm 5 \mathrm{MHz}$. This accelerator generates electron beam pulses of $0.375 \mathrm{~ms}$ duration, up to 0.32 A current peak intensity and up to $6 \mathrm{~mA}$ mean current intensity. The cross-sectional size of the scanned EB at the ILU-6M vacuum window exit is $1100 \mathrm{~mm} \times 65 \mathrm{~mm}$. The EB effects are related to the absorbed dose (D), expressed in Gray or $\mathrm{J} \mathrm{kg}^{-1}$. The single pass dose with conveyor under the ILU-6M scanner is adjustable from $12.5 \mathrm{kGy}$ to $50 \mathrm{kGy}$. The main characteristics of the ILU-6M electron accelerator are presented in Table 3. 


\begin{tabular}{|l|l|}
\hline \multicolumn{1}{|c|}{ Characteristic } & \multicolumn{1}{c|}{ Value } \\
\hline EA energy & $1.8 \mathrm{MeV}$ \\
\hline EA power in impulse & $0-1 \mathrm{~A}$ \\
\hline EA impulse duration & $\tau=500 \mu \mathrm{s}$ \\
\hline EA impulse repeat frequency & $2,3,510,15,25,50 \mathrm{~Hz}$ \\
\hline Mean power & $0-6 \mathrm{~mA}$ \\
\hline Maximum mean power & $10.8 \mathrm{~kW}$ \\
\hline Electron scattering method & Electromagnetic scanning device \\
\hline $\begin{array}{l}\text { Useful section of EA field at scanning device } \\
\text { output }\end{array}$ & 100 cm x 6.5 cm \\
\hline Conveyor belt for samples to be irradiated \\
with the following characteristics: & $\begin{array}{l}\text { Moving speed, Vbelt=1.56-12.8 cm/s; } \\
\text { Dimensions: length }=125 \mathrm{~mm} ; \text { width }=290 \\
\text { mm; thickness }=160 \mathrm{~mm} ; \\
\text { Distance between terminals: } 1282 \mathrm{~mm} \\
\text { Distance from the scanning device output } \\
\text { Window: } \mathrm{H}=100-500 \mathrm{~mm} ; \\
\text { Dimensions of sample holder: } 500 \mathrm{~mm} \mathrm{x} \\
300 \text { mm (with possibility of extension } \\
\text { up to } 1500 \text { mm } x 600 \text { mm) }\end{array}$ \\
\hline
\end{tabular}

Table 3. The main characteristics of cavity electron accelerator ILU-6M

The Experimental installation A uses the multimode rectangular cavity of a mechanical and electrical proper modified MW oven (MEM-MWO) of $2.45 \mathrm{GHz}$ and $710 \mathrm{~W}$ output power. The conventional operation of the $2.45 \mathrm{GHz}$ oven magnetron was properly modified in order to permit the use of an electronic regulator that ensures variable magnetron output power (Martin et al., 2001). Microwaves are generated as $10 \mathrm{~ms}$ pulses at $50 \mathrm{~Hz}$ repetition rate. For MW irradiation was used the SAR values which prevents during $\mathrm{MW}+\mathrm{EB}$ irradiation the rise of the samples final temperature above $60-70^{\circ} \mathrm{C}$.

The rubber samples were obtained from raw rubber mixtures, as compressed sheets of $2 \mathrm{~mm}$ in the polyethylene foils to minimize oxidation. For radiation treatments the sheets were cut in rectangular shape of two different sizes: type 1 of $0.1 \mathrm{~m} \times 0.03 \mathrm{~m}^{2}$ and type 2 of $0.15 \times 0.15$ $\mathrm{m}^{2}$. The treatment was performed with layers of 10 sandwiched type 1 sheets irradiated using ALIN-10 accelerator and three sandwiched type 2 sheets using the ILU-6M accelerator.

The EB effects are related to the absorbed dose (D) expressed in Gray or J kg-1 and absorbed dose rate $\left(D^{*}\right)$ expressed in Gy s${ }^{-1}$ or $\mathrm{J} \mathrm{kg}^{-1} \mathrm{~s}^{-1}$. The MW effects are related to SAR (Specific Absorption Rate, expressed in W. $\mathrm{kg}^{-1}$ ) which is equivalent to $\mathrm{D}^{*}$ and SA (Specific Absorption, expressed in $\mathrm{J} \mathrm{kg}^{-1}$ ) which is equivalent to D.

According to the Technical Report Series No. 277 (Andreo et al., 1997), the absorbed dose is the major parameter in the accelerated electron radiation. The vulcanizing and grafting process performances are provided by the severe control of this parameter. The relation defining the absorbed dose is: 


$$
\mathrm{D}=\mathrm{d} \varepsilon / \mathrm{dm}
$$

where:

$\mathbf{d} \boldsymbol{\varepsilon}$ is the mean energy given up by the ionizing radiation to the mass amounts $\mathbf{d m}$ of the substance interacting with this ionizing radiation.

$\mathbf{d m}$ is emphasized to be very low but not so low that the mean energy $\mathbf{d} \boldsymbol{\varepsilon}$ given up by the radiation would undergo a significant fluctuation.

Absorbed dose is measured in $\mathbf{J} / \mathbf{k g}$. The SI unit measure for the absorbed dose is the gray (Gy): $1 \mathrm{~Gy}=1 \mathrm{Joule} / \mathrm{kg}$. The rad unit is also used, with the following relation between the Gy and rad: $1 \mathrm{~Gy}=\mathbf{1 0 0}$ rad. A relevant example: a material irradiated by $2 \mathrm{Mrad}$ (20 kGy) means that AE (accelerated electron beam) have deposited $2.10^{8}$ ergs or about $10^{19} \mathrm{eV}$ per gram substance.

After irradiation the samples are analyzed by mechanical testing. Tensile strength and tear strength tests were carried out with a Schoppler strength tester with testing speed 460 $\mathrm{mm} / \mathrm{min}$, using dumb-bell shaped specimens according to ISO 37/1997, respectively angular test pieces (type II) in according to ISO 34-1/2000. Hardness was measured by using a hardener tester according to ISO 7619/2001. Elasticity was evaluated with a test machine of type Schob. The cure characteristics of the compounds were measured at $160^{\circ} \mathrm{C}$ using an oscillating disk rheometer (Monsanto), according to the SR ISO 3417/1997.

\section{Electron beam and microwaves processing of elastomers/rubbers with polyfunctional monomers}

\subsection{Aspects regarding crosslinking of a natural rubber (NR) blend}

Natural rubber is a heavily researched material. The outstanding strength of natural rubber has maintained its position as the preferred material in many engineering applications. It has a long fatigue life and high strength even without reinforcing fillers. Other than for thin sections it can be used to approximately $100{ }^{\circ} \mathrm{C}$, and sometimes above. It can maintain flexibility down to $-60{ }^{\circ} \mathrm{C}$ if compounded for the purpose. It has good creep and stress relaxation resistance and is low cost. Its chief disadvantage is its poor oil resistance and its lack of resistance to oxygen and ozone, although these latter disadvantages can be ameliorated by chemical protection. An natural rubber structure is illustrated in Figure 1.

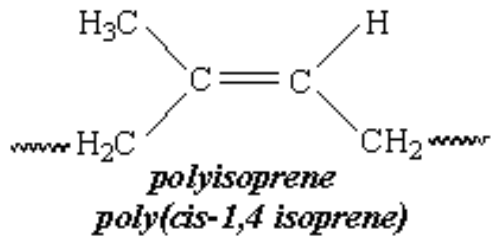

Figure 1. Chemical structure of natural rubber (NR) 
The vulcanisation of natural rubber (NR) by sulphur in presence of organic accelerator is a complicated process. The mechanism of vulcanisation and its acceleration depends on the structure of the rubber, type and concentration of accelerators and activators (zinc oxide and fatty acid) and on the thermodynamics of each particular reaction. The chemistry of vulcanisation is complex and the resulting crosslinks may be mono-, di-, tri- or higher polysulphides, with a proportion which is among others largely determined by the vulcanisation system, the cure time and the temperature.(Stelescu et al., 2010).

This section presents the influence of the vulcanization method - of the crosslinking mechanism - on the characteristics of a natural rubber blend (Stelescu et al., 2010) .

The following raw materials have been used: Crep natural rubber, Ultrasil VN3 precipitated silica (50 phr), zinc oxide quality I (5 phr), stearic acid (0.5 phr), polyethylene glycol coupling agent ( 3 phr), Irganox 1010 antioxidant (1 phr). For crosslinking blends, the following were used: Perkadox 40 benzoyl peroxide ( $8 \mathrm{phr}$ ) - for peroxide vulcanization; sulphur (1.5 phr) and vulcanization accelerators (tetramethyl thiuram disulfide TMTD (1 phr) and mercaptobenzothiazol MBT (0.5 phr) - for sulphur vulcanization; accelerated electrons (EB) and polyfunctional monomer - trimethylopropane trimethacrylate TMPT DL $75 \mathrm{C}$ (6 phr) for electron beam vulcanization.

Blends have been made by means of blending technique, on a laboratory roll with electric heating at $65-70^{\circ} \mathrm{C}$, total blend time of $12^{\prime}$. Plates for physical-mechanical determinations have been made by means of hydraulic press. Blends crosslinked with peroxide or with sulphur and accelerators have been reticulated at $160^{\circ} \mathrm{C}$ and vulcanization time was chosen depending on curves obtained on the Monsando rheometer (rheologic characteristics) of blends in order to obtain the following blend samples: subvulcanized ( $\left.\mathrm{T}_{50}\right)$, vulcanized $\left(\mathrm{T}_{90}\right)$ and supravulcanized $\left(\mathrm{T}_{140}\right)$. Thus, the time needed to obtain $\mathrm{T}_{50}$ and $\mathrm{T}_{90}$ blends was determined from rheograms and corresponds to $T_{50}$ and $T_{90}$ in Table 1 , and the time needed to obtain T 140 supravulcanized blends was $22^{\prime}$ for both types of blends. Plates for irradiation were modeled by pressing at low temperatures of maximum $100^{\circ} \mathrm{C}$ for $3^{\prime}$.

The EB vulcanization rubber processing is performed with the accelerator ILU-6M of 1.8 $\mathrm{MeV}$ and $10.8 \mathrm{~kW}$. For EB treatment the rubber sheets were cut in rectangular shape of 0.15 $\mathrm{x} 0.15 \mathrm{~m}^{2}$. The layers of three sandwiched sheets were irradiated by repeatedly passing on a conveyor under the ILU-6M scanner. Samples were irradiated with 5, 10, 15 and $20 \mathrm{Mrad}$ respectively (1 Mrad $=10 \mathrm{kGy})$.

Rheologic characteristics of blends crosslinked with peroxide (symbol NRI-P) and with sulphur (symbol NPI-S) respectively, obtained by means of Monsanto rheometer (Table 4), show that the minimum moment and the maximum moment have high values because the charge and the other ingredients introduced in the blend have led to an increase of blend viscosity, and as a result, the blend opposes a high resistance force to the rotation of the oscillating disk of Monsanto rheometer. Physical-mechanical properties of obtained blends are presented in Table 5, Table 6 and Table 7. 


\begin{tabular}{|c|c|c|c|c|}
\hline Blend name & $\begin{array}{c}\text { Momentmin. } \\
(d N / m)\end{array}$ & $\begin{array}{c}\text { Momentmax. } \\
(d N / m)\end{array}$ & $T_{90}$ & $T_{50}$ \\
\hline NRI-P & 22 & 48.9 & $12^{\prime} 30^{\prime \prime}$ & $3^{\prime} 45^{\prime \prime}$ \\
\hline NRI-S & 31 & 59.2 & $12^{\prime} 30^{\prime \prime}$ & $1^{\prime} 45^{\prime \prime}$ \\
\hline
\end{tabular}

Table 4. Rheologic characteristics of blends

\begin{tabular}{|l|c|c|c|c|c|c|}
\hline \multirow{2}{*}{\multicolumn{1}{|c|}{ Characteristics / Symbol blend }} & \multicolumn{3}{c|}{ NRI-P } & \multicolumn{3}{c|}{ NRI-S } \\
\cline { 2 - 8 } & $T_{50}$ & $T_{90}$ & $T_{140}$ & $T_{50}$ & $T_{90}$ & $T_{140}$ \\
\hline Hardness, ${ }^{\circ}$ ShA & 80 & 83 & 85 & 75 & 74 & 74 \\
\hline Elasticity, \%, & 39 & 38 & 41 & 36 & 34 & 32 \\
\hline Tensile stress at 100\%elongation, N/mm ${ }^{2}$ & 3.3 & 4.6 & 5.26 & 2.4 & 1.82 & 1.9 \\
\hline Tensile strength, N/mm2 & 12.7 & 10.3 & 6.6 & 20.6 & 17.6 & 16.8 \\
\hline Elongation at break, \% & 346 & 246 & 153 & 600 & 640 & 646 \\
\hline Permanent set, \% & 42.5 & 32.9 & 36.8 & 81.7 & 62 & 62 \\
\hline Tear strength, N/mm & 20 & 14.6 & 7.3 & 46 & 42 & 43 \\
\hline
\end{tabular}

Table 5. Physical-mechanical properties of NR rubber blends vulcanized with peroxide (NRI-P), and sulphur and accelerators (NRI-S)

\begin{tabular}{|c|c|c|c|c|}
\hline \multirow{2}{*}{$\begin{array}{c}\text { Characteristics / Symbol blend/ } \\
\text { Irradiation dose }\end{array}$} & \multicolumn{4}{|c|}{ NRI } \\
\hline & $5 \mathrm{Mrad}$ & 10Mrad & 15Mrad & 20Mrad \\
\hline 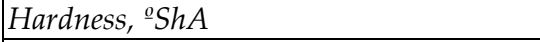 & 50 & 55 & 56 & 66 \\
\hline Elasticity, \% & 28 & 28 & 30 & 32 \\
\hline Tensile stress at $100 \%$ elongation, $\mathrm{N} / \mathrm{mm}^{2}$ & 0.73 & 1 & 1.3 & 1.7 \\
\hline Tensile strength, $\mathrm{N} / \mathrm{mm}^{2}$ & 4 & 5.3 & 8 & 9.3 \\
\hline Elongation at break, \% & 500 & 520 & 533 & 487 \\
\hline Permanent set, \% & 148 & 110 & 80 & 61 \\
\hline Tear strength, $\mathrm{N} / \mathrm{mm}$ & 14.5 & 21.5 & 45.5 & 50.5 \\
\hline
\end{tabular}

Table 6. Physical-mechanical properties of NR rubber blends vulcanized with EA (NRI)

\begin{tabular}{|l|c|c|c|c|}
\hline \multirow{2}{*}{\multicolumn{1}{c|}{$\begin{array}{c}\text { Characteristics / Symbol blend/ } \\
\text { Irradiation dose }\end{array}$}} & \multicolumn{4}{c|}{ NRI-TMPT } \\
\cline { 2 - 5 } & $5 \mathrm{Mrad}$ & $10 \mathrm{Mrad}$ & $15 \mathrm{Mrad}$ & 20Mrad \\
\hline Hardness, ${ }^{\circ}$ ShA & 50 & 76 & 81 & 81 \\
\hline Elasticity, \% & 30 & 31 & 34 & 36 \\
\hline Tensile stress at 100\%elongation, N/mm ${ }^{2}$ & 0.82 & 3.1 & 4 & 5.2 \\
\hline Tensile strength, N/mm & 3.6 & 13.8 & 15.9 & 14.6 \\
\hline Elongation at break, \% & 527 & 427 & 407 & 347 \\
\hline Permanent set, \% & 157 & 37 & 30 & 23 \\
\hline Tear strength, N/mm & 18 & 67.5 & 72.5 & 72.5 \\
\hline
\end{tabular}

Table 7. Physical-mechanical properties of NR rubber blends vulcanized with EA in the presence of TMPT (NRI-TMPT) 
Comparing physical-mechanical properties of subvulcanized ( $\left.\mathrm{T}_{50}\right)$, vulcanized $\left(\mathrm{T}_{90}\right)$ and supravulcanized ( $\left.\mathrm{T}_{140}\right)$ samples from each type of NRI-S and NRI-P blend (table 5), it is noticed that: (a) in the case of blends crosslinked with peroxides, as the vulcanization time increases, hardness, elasticity and tensile stress at $100 \%$ elongation increase and tensile strength, elongation at break, permanent set and tear strength decrease; (b) for blends crosslinked with sulphur and accelerators, as the vulcanization time increases, a slight decrease of hardness, elasticity, tensile stress at $100 \%$ elongation, tensile strength, permanent set and tear strength, and a slight increase of elongation at break take place; (c) hardness, elasticity and tensile stress at 100\% elongation of blends with ingredients vulcanized with sulphur are lower than those vulcanized with peroxide, instead, tensile strength, tear strength, elongation at break and permanent set have higher values; (d) characteristics of blends crosslinked with peroxide decrease significantly when increasing vulcanization time compared to samples obtained through other vulcanization methods, indicating degradation of polymer chain in the presence of peroxide; (e) physical-mechanical properties of subvulcanized, vulcanized and supravulcanized samples of NR blend depend on the crosslinking technique and mechanism.

Comparing blends cross-linked with peroxide to NRI and NRI-TMPT type (table 6 and table 7 ), irradiated with EA (in both cases crosslinking is done by radicalic mechanism), it can be noticed that: (a) the optimal dose needed can be $20 \mathrm{Mrad}$ and 10-15 Mrad respectively in the case of blends containing 6 phr TMPT; (b) upon increasing the irradiation dose, hardness, elasticity, tensile stress at $100 \%$ elongation, tensile strength and tear strength increase and permanent set decreases; (c) blends crosslinked with EA in the presence of TMPT exhibit superior values of tear strength, have good values of permanent set - similar to those obtained through other methods - indicating an efficient crosslinking, and tensile strength, elongation at break, hardness, elasticity and tensile stress at $100 \%$ elongation have values ranging between those obtained in vulcanization with peroxide and those made by vulcanization with sulphur and accelerators; (d) natural rubber blends containing $6 \mathrm{phr}$ TMPT irradiated at $15 \mathrm{Mrad}$ and $20 \mathrm{Mrad}$ respectively, exhibit superior physical-mechanical properties compared to control blend NRI-P tip $\mathrm{T}_{90}$ (obtained by vulcanization with peroxide). Based on results obtained and existing literature studies, reaction mechanisms are suggested for crosslinking natural rubber using the crosslinking systems presented above.

Vulcanization with sulphur and accelerators of NR (Figure 2) is done in general by ionic mechanism and leads to the formation of sulphur bridges between (C-Sx-C) macromolecules or cyclic combination of sulphur. At high temperatures, desulphuration takes place, determining the formation of shorter sulphur bridges. As a consequence of thermal instability of sulphurs, NR vulcanized with sulphur can be devulcanized in the presence of disulphur diaryls or amines, at temperatures of over $300^{\circ} \mathrm{C}$ (Stelescu et al., 2010).

Vulcanization with peroxides (Figure 3) is done by radicalic mechanism when bonds form between C-C macromolecules; crosslinking is initiated by thermal decomposition of peroxide, which is considered the determining stage of crosslinking speed. Then free radicals formed extract hydrogen atoms from natural rubber chains in order to form 
macroradicals (Stelescu et al., 2010; Hofmann, 1967). Macroradicals recombine forming crosslinked structure.

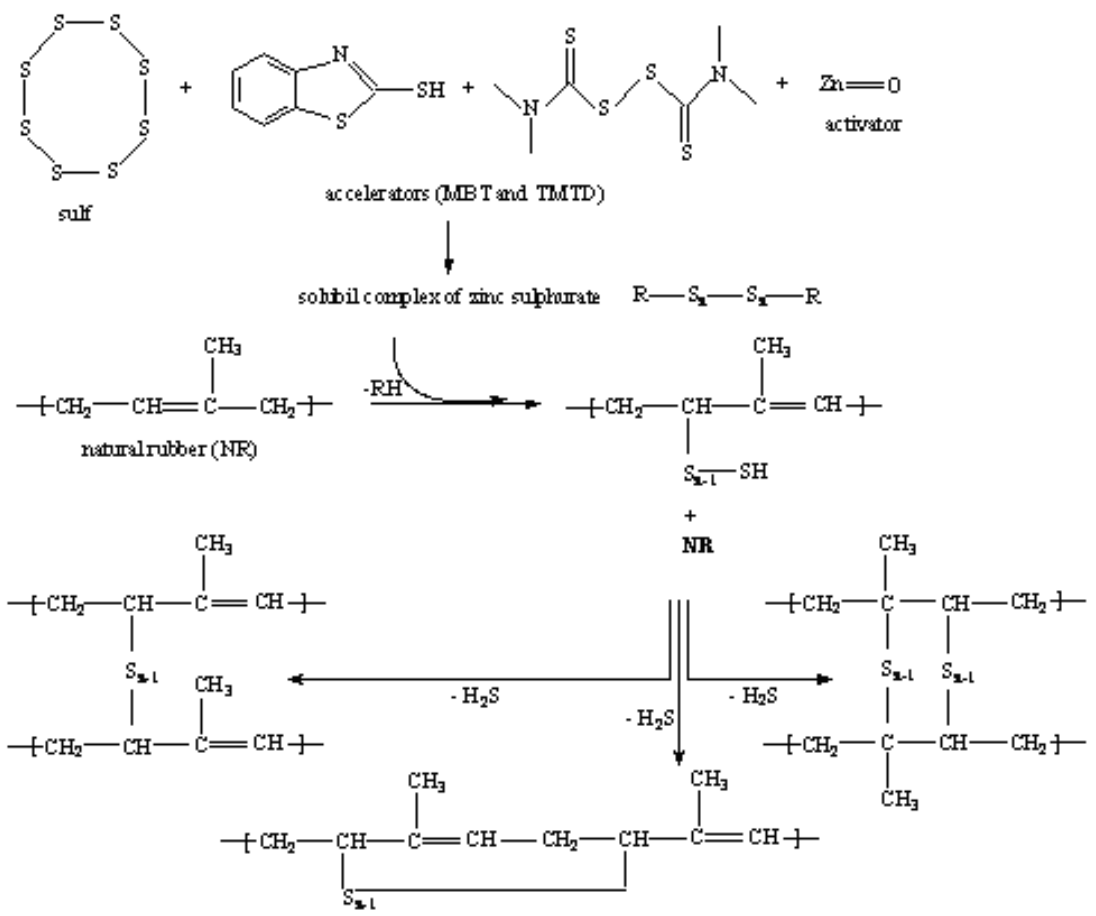

Figure 2. Reaction scheme - Mechanism of crosslinking natural rubber with sulphur and accelerators (Stelescu et al., 2010).
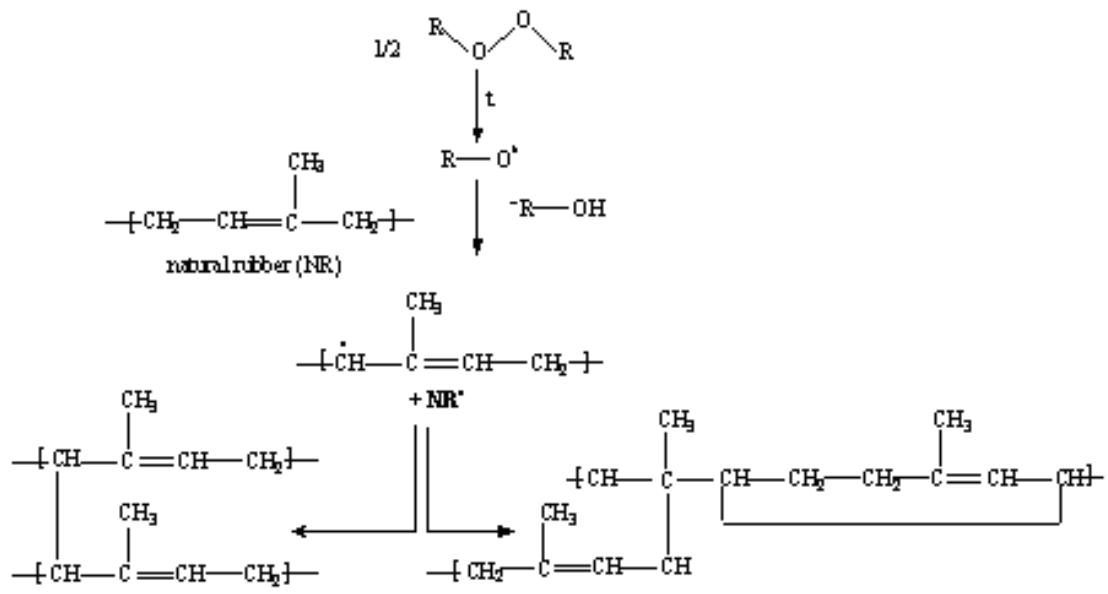

Figure 3. Reaction scheme - Mechanism of crosslinking natural rubber with peroxides (Stelescu et al., 2010) . 


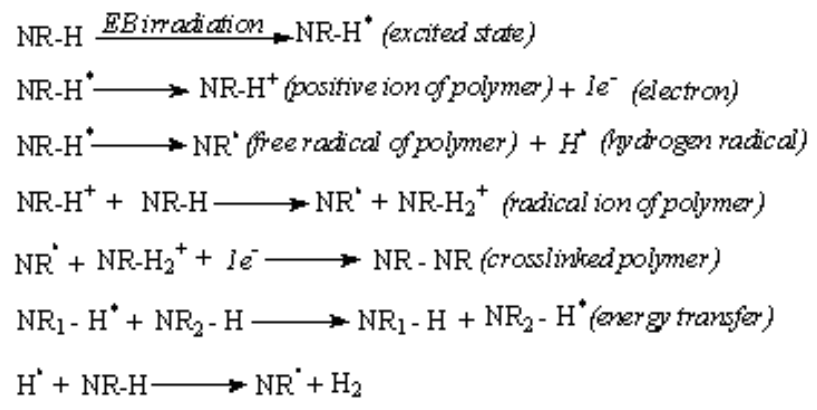

Figure 4. Reaction scheme - Mechanism of crosslinking natural rubber with EB

Elastomer crosslinking by means of EB (Figure 4) is done without heating and in the absence of vulcanization agents. The chemistry of the process is based on macroradical formation from elastomer chains, which recombine, causing structuring. Isomerisations, double bond migrations, cyclizations, destructions etc. take place simultaneously with vulcanization. The reaction mechanism is similar to that presented in crosslinking with peroxides, but in this case, reaction initiation is due to the action of EB (Boye, 2008).

\subsection{The influence of trimethylol-propane trimethacrylate (TMPT) co-agent on the mechanical properties of the natural rubber (NR) cross-linked by EB irradiation}

In the following experiment (Stelescu \& Manaila, 2007) the natural rubber blends were grafted and crosslinked by means of the accelerated electrons in the presence of a multifunctional monomer - trimethylol-propane trimethacrylate (TMPT), and the influences of the trimethylol-propane trimethacrylate (TMPT) percentage and accelerated electron irradiation dose on the physical-mechanical characteristics of the natural rubber (NR) blends were investigated.

The used materials were: natural rubber Crep 1X (NR), trimethylol-propane trimethacrylate TMPT DL 75 (TMPT), Ultrasil VN3 precipitated silica (50 phr), zinc oxide quality I (5 phr), stearic acid (0.5 phr), polyethylene glycol coupling agent (3 phr), Irganox 1010 antioxidant (1 phr) and benzoyl peroxide Perkadox 14-40B-GR ( $8 \mathrm{phr}$ ) as curing agent for the control blend.Natural rubber blends containing 0, 3, 6 and 9 phr of TMPT were prepared by blending on a laboratory roller mill. From these samples in a shape of plates were obtained by means of hydraulic press at $150 \mathrm{MPa}$ and $100^{\circ} \mathrm{C}$. The resulted plates were treated by irradiation, using the accelerator ALIN-10. The accelerated electrons dose rate was established to $2.4 \mathrm{kGy} / \mathrm{min}$ in order to accumulate $5 \mathrm{Mrad}, 10 \mathrm{Mrad}, 15 \mathrm{Mrad}$ and $20 \mathrm{Mrad}$ respectively ( $1 \mathrm{Mrad}=10 \mathrm{kGy}$ ). The control blend was obtained with benzoyl peroxide as curing agent. The blend was prepared on a laboratory roller mill and the control sample curing was accomplished on hydraulic press at $160^{\circ} \mathrm{C}$. The best curing time (12'30") was determined by means of a Monsanto Rheometer. 
Figures 5-10 illustrate the changes in physical-mechanical characteristics depending on the TMPT percentage in the blend and irradiation dose. Hardness (figure 5) increases as the irradiation dose and TMPT percentage increase; the hardness values for the blends with 6 and 9 phr of TMPT each irradiated at 15 and 20 Mrad are similar to those of the control blend (83hA ${ }^{\circ}$. Tensile stress at $100 \%$ elongation (figure 6) for the blends with 6 and 9 phr TMPT at an irradiation dose of 20 Mrad shows a higher value than tensile stress at $100 \%$ elongation for the control sample $\left(4,6 \mathrm{~N} / \mathrm{mm}^{2}\right)$. Tensile strength (figure 7) for the samples from blends with 6 and 9 phr TMPT, irradiated by means of accelerated electrons shows higher values than for the control sample $\left(10,3 \mathrm{~N} / \mathrm{mm}^{2}\right)$, even at an irradiation dose of 10 Mrad. Values of the elongation at break (figure 8) for the samples irradiated with accelerated electrons are higher than those for the control sample (246\%). This aspect decreases as the irradiation dose and TMPT percentage increase. Permanent set (figure 9) decreases as the irradiation dose and TMPT percentage increase; for the blends with 6 and 9 phr of TMPT irradiated with 15 and 20 Mrad, the permanent set values are lower than those for the control sample $(14,6 \%)$, revealing a high crosslinking level. Tear strength (figure 10) for the samples from the blends irradiated with accelerated electrons shows higher values than those for the control sample $(14,6 \mathrm{~N} / \mathrm{mm})$.

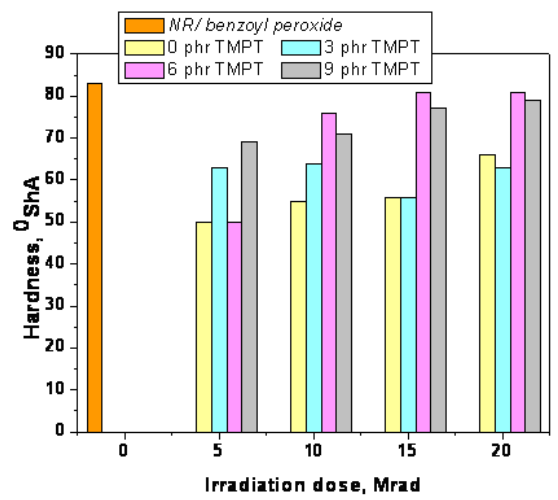

Figure 5. Changes in hardness versus the irrad iation dose and TMPT percentage

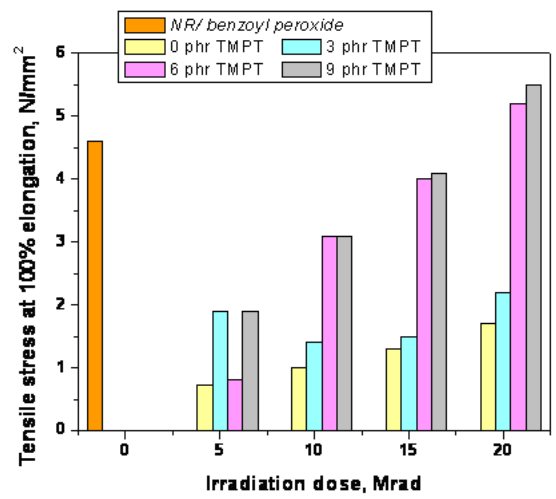

Figure 6. Changes in tensile stress at 100\% elongation versus the irradiation dose and TMPT percentage 


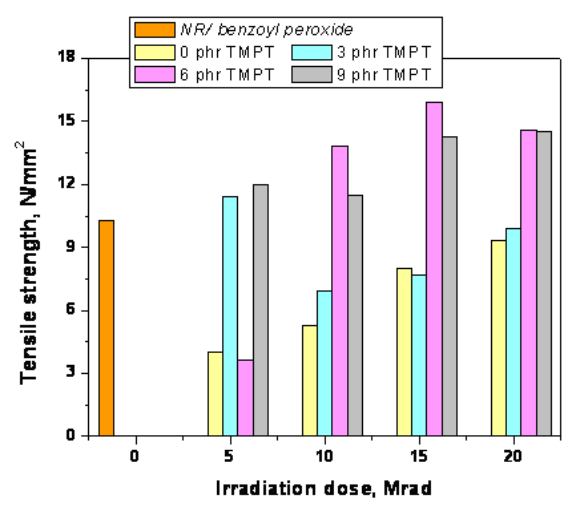

Figure 7. Changes in tensile strength versus the irradiation dose and TMPT percentage

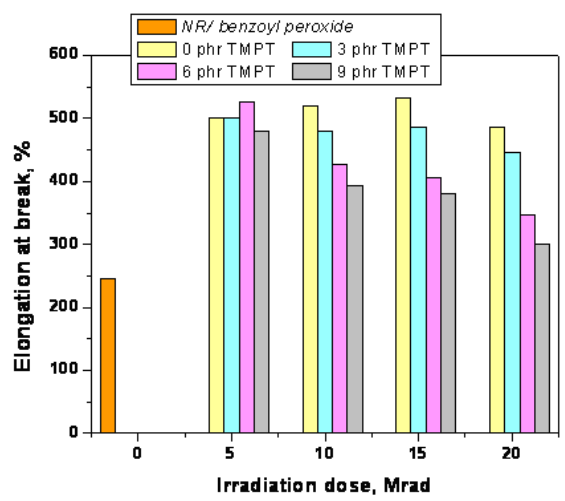

Figure 8. Changes in elongation at break versus the irradiation dose and TMPT percentage

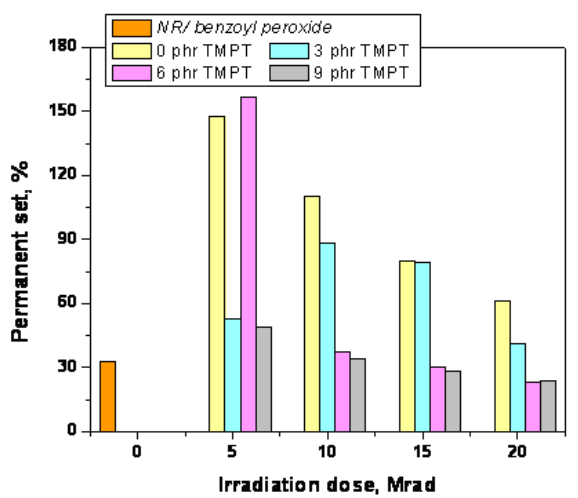

Figure 9. Changes in permanent set versus the irradiation dose and TMPT percentage 


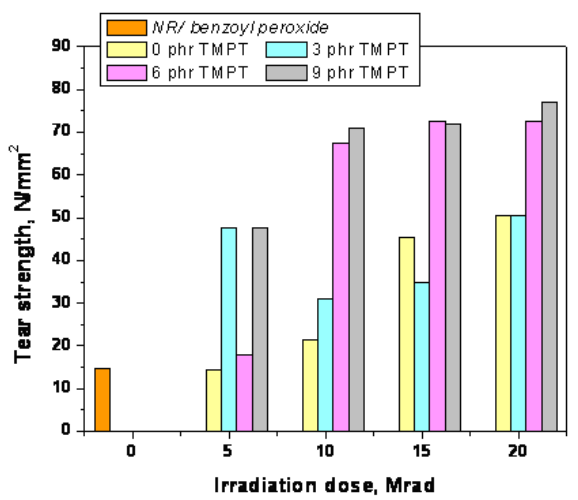

Figure 10. Changes in tear strength versus the irradiation dose and TMPT percentage

As a conclusion, the natural rubber blends containing 6 and 9 phr of TMPT irradiated each of them at 20 Mrad have shown higher physical-mechanical characteristics than those for the control sample (obtained by curing with peroxide at $160^{\circ} \mathrm{C}$ ). This proves the advantages of a new processing technique for the NR blends resulting in 10 times shorter curing time, removing the curing agents, and lack of wastes.

\subsection{Characteristics of natural rubber (NR) blends cross-linked by electron beam and microwave irradiation}

Crosslinking of elastomers or rubbers by electron beam (EB) and microwave (MW) radiations could be a new method for improve their mechanical properties. Interaction of each of the two physical systems, EB and MW, with a substance has revealed their ability for changing physical and chemical proprieties of the treated substance. Therefore, the physical and chemical effects of the EB and MW radiation have drawn high interest, resulting in a large industrial application range of the new materials with improved characteristics. In the following we present the effect of the polyfunctional monomers (PFMs) on the mechanical properties of the NR (natural) rubber crosslinked by electron beam (EB) and microwave processing (Manaila, Stelescu et al., 2011).

The following materials were used in the study: natural rubber Crep 1X; triallylcyanurate TAC DL 70 (3 phr); triallylisocyanurate TAIC DL 70C (3 phr); trimethylopropanetrimethacrylate TMPT DL 75 (3 phr) and zinc-diacrylate ZDA GR 75 (3 phr). Blends were prepared on an electrically heated laboratory roller mill. For preparation of NR with polyfunctional monomers, the blend constituents were added in the following sequence and amounts: 100 phr NR and 3 phr polyfunctional monomers (TAC, TAIC, TMPT and ZDA respectively). Process variables: temperature $25-50^{\circ} \mathrm{C}$, friction $1: 1.1$, and total blending time 5 min. Plates required for physico-mechanical tests were obtained by pressing in a hydraulic press at $110 \pm 5^{\circ} \mathrm{C}$ and $150 \mathrm{MPa}$. Dibenzoyl peroxide vulcanized samples were prepared similarly to the experimental ones with the following specifications: $8 \mathrm{phr}$ of dibenzoyl 
peroxide as vulcanizing agent was added and the blend vulcanization was achieved in a hydraulic press at $160^{\circ} \mathrm{C}$; the vulcanization time was measured by means of Monsanto Rheometer. The resulted plates were treated by irradiation, using the accelerator ILU - $6 \mathrm{M}$. For EB and EB+MW treatments the rubber samples were cut as compressed sheets of $2 \mathrm{~mm}$ thick in the polyethylene foils to minimize oxidation. The layers of three sandwiched sheets were irradiated by repeatedly passing on a conveyor under the ILU-6M scanner.

The mechanical properties of samples are summarized in Tables 8-11.

\begin{tabular}{|c|c|c|c|c|}
\hline \multirow{2}{*}{ Mechanical characteristics } & \multirow{2}{*}{$\begin{array}{c}\text { BP } \\
\text { vulcanization } \\
\text { NR - P } \\
\end{array}$} & \multicolumn{2}{|c|}{ EB vulcanization } & \multirow{2}{*}{$\begin{array}{c}\text { EB+MW } \\
\text { vulcanization } \\
5 \mathrm{Mrad}+55^{\prime}\end{array}$} \\
\hline & & 5 Mrad & 10 Mrad & \\
\hline Elasticity, $\%$ & 50 & 44 & 44 & 42 \\
\hline $\begin{array}{l}\text { Tensile stress at } 100 \% \text { elongation, } \\
\mathrm{N} / \mathrm{mm}^{2}\end{array}$ & - & 0.3 & 0.4 & 0.19 \\
\hline Tensile strength, $\mathrm{N} / \mathrm{mm}^{2}$ & 0.9 & 0.8 & 0.9 & 4.6 \\
\hline Elongation at break, \% & 87 & 487 & 300 & 935 \\
\hline Permanent set, $\%$ & 5 & 15 & 8 & 19 \\
\hline Tear strength, N/mm & 2 & 9.5 & 14.5 & 11 \\
\hline
\end{tabular}

Table 8. Physical-mechanical characteristics of blends: NR+TAC

\begin{tabular}{|c|c|c|c|c|}
\hline \multirow{2}{*}{ Mechanical characteristics } & \multirow{2}{*}{$\begin{array}{c}\text { BP } \\
\text { vulcanization } \\
\text { NR - P }\end{array}$} & \multicolumn{2}{|c|}{ EB vulcanization } & \multirow{2}{*}{$\begin{array}{c}E B+M W \\
\text { vulcanization } \\
5 \text { Mrad + 55' }\end{array}$} \\
\hline & & 5 Mrad & 10 Mrad & \\
\hline Elasticity, \% & 68 & 42 & 42 & 50 \\
\hline Tensile stress at $100 \%$ elongation, $\mathrm{N} / \mathrm{mm}^{2}$ & - & 0.4 & 0.4 & 0.21 \\
\hline Tensile strength, $\mathrm{N} / \mathrm{mm}^{2}$ & 0.96 & 0.7 & 2.2 & 4.8 \\
\hline Elongation at break, \% & 87 & 387 & 647 & 850 \\
\hline Permanent set, $\%$ & 9 & 11 & 13 & 15 \\
\hline Tear strength, N/mm & 2.5 & 7 & 13 & 13 \\
\hline
\end{tabular}

Table 9. Physical-mechanical characteristics of blends: NR+TAIC

\begin{tabular}{|c|c|c|c|c|}
\hline \multirow{2}{*}{ Mechanical characteristics } & \multirow{2}{*}{$\begin{array}{c}\text { BP } \\
\text { vulcanization } \\
\text { NR - P }\end{array}$} & \multicolumn{2}{|c|}{ EB vulcanization } & \multirow{2}{*}{$\begin{array}{c}E B+M W \\
\text { vulcanization } \\
5 \text { Mrad }+55^{\prime}\end{array}$} \\
\hline & & 5 Mrad & 10 Mrad & \\
\hline Elasticity, \% & 68 & 48 & 53 & 48 \\
\hline Tensile stress at $100 \%$ elongation, $\mathrm{N} / \mathrm{mm}^{2}$ & - & 0.4 & 0.4 & 0.29 \\
\hline Tensile strength, $\mathrm{N} / \mathrm{mm}^{2}$ & 0.82 & 3.6 & 8.3 & 8.7 \\
\hline Elongation at break, \% & 60 & 673 & 727 & 785 \\
\hline Permanent set, $\%$ & 3 & 9 & 7 & 14 \\
\hline Tear strength, N/mm & 1.39 & 13.5 & 21 & 13 \\
\hline
\end{tabular}

Table 10. Physical-mechanical characteristics of blends: NR+TMPT 


\begin{tabular}{|c|c|c|c|c|}
\hline \multirow{2}{*}{ Mechanical characteristics } & \multirow{2}{*}{$\begin{array}{c}\text { BP } \\
\text { vulcanization } \\
\mathrm{NR}-\mathrm{P} \\
\end{array}$} & \multicolumn{2}{|c|}{ EB vulcanization } & \multirow{2}{*}{$\begin{array}{c}E B+M W \\
\text { vulcanization } \\
5 \text { Mrad + 55' }\end{array}$} \\
\hline & & 5 Mrad & 10 Mrad & \\
\hline Elasticity, \% & 66 & 46 & 50 & 50 \\
\hline Tensile stress at $100 \%$ elongation, $\mathrm{N} / \mathrm{mm}^{2}$ & - & 0.39 & 0.51 & 0.26 \\
\hline Tensile strength, $\mathrm{N} / \mathrm{mm}^{2}$ & 1.3 & 0.99 & 3 & 3.7 \\
\hline Elongation at break, \% & 140 & 340 & 607 & 675 \\
\hline Permanent set, $\%$ & 2 & 10 & 6 & 11 \\
\hline Tear strength, N/mm & 4.5 & 7.5 & 18 & 18 \\
\hline
\end{tabular}

Table 11. Physical-mechanical characteristics of blends: NR+ZDA

Analyzing the mechanical characteristics obtained from the EB cross-linked samples compared with those of cross-linked with peroxide mixtures in the presence of the same types of PFMs can be observed: (1) significant improvements in tensile strength (between $130 \%$ for NR+TAIC and NR+ZDA at $10 \mathrm{Mrad}$, and $912 \%$ for NR+TMPT at $5 \mathrm{Mrad}$; (2) elongation at break increases, for all polyfunctional monomers type, the smallest increase being $142 \%$ for NR+ZDA at $5 \mathrm{Mrad}$ and highest $1112 \%$ for NR+TMPT at $10 \mathrm{Mrad}$; (3) tear strenght increases with radiation dose, (between 180\% for NR+TAIC at $5 \mathrm{Mrad}$, and $1410 \%$ for NR+TMPT at $10 \mathrm{Mrad}$; (4) for all samples was noticed a decrease in elasticity.

Relatively low permanent set values indicate a good return to its original shape after applying a force, so an efficient curing for all samples. In conclusion, even at a dose of 5 Mrad was achieved an efficient crosslinking of NR. The polyfunctional monomer influence on these parameters for the samples vulcanized with EB is the following: TMPT $>$ ZDA $>$ TAC > TAIC.

Comparing the mechanical characteristics obtained from the EA+MW cross-linked samples with those of cross-linked with peroxide mixtures in the presence of the same types of MP can be observed a significant improvement in tensile strength (up to $411 \%$ for NR+TAC, $400 \%$ for NR+TAIC, $960 \%$ for NR+TMPT and $184 \%$ for NR+ZDA), in elongation at break (up to $974 \%$ for NR+TAC, $877 \%$ for NR+TAIC, $1208 \%$ for NR+TMPT and $382 \%$ for NR+ZDA) and tear strenght (up to $450 \%$ for NR+TAC, $420 \%$ for NR+TAIC, $835 \%$ for TMPT and $300 \%$ for NR+ZDA). The order of influence of polyfunctional monomers on the studied parameters for $\mathrm{EA}+\mathrm{MW}$ is identical to that in the case of irradiation with EA (TMPT $>$ ZDA $>$ TAC > TAIC).

Improved characteristics of hardened mixtures with EA and EA + MW from the hardened peroxide is due on the one hand the advantages of accelerated electrons (the process is very fast, and due to high penetration power of radiation there is an effective and uniform curing), and on the other hand, the advantages of microwave (promote a narrow distribution of the molecular masses, as the crosslinking occurs simultaneously in the bulk of material because of the microwave interaction with all material under irradiation; promote fast crosslinking processes) (MGM Rubber Company-Research and Development, 2007; Martin, 2002). Also, due to reduced processing time, it is removed the degradation due to thermal degradation at high temperature elastomer maintenance of about $160^{\circ} \mathrm{C}$ for $10-30 \mathrm{~min}$. 
Analyzing the characteristics influence of polyfunctional monomers type, can be seen that the best results were obtained by using TMPT followed by ZDA (coagents curing Type I). Type I polyfunctional monomers are highly reactive and increase the rate and state of cure. Type II (TAC and TAIC) polyfunctional monomers increase the state of cure only. Also, the influence of polyfunctional monomers to increasing the mechanical characteristics is determined by the reactivity, the number of reactive groups (functionality): TMPT has functionality three and ZDA has functionality two (Boye, 2008; Henning, 2008).

\subsection{Characteristics of materials based on chlorinated polyethylene (CPE) obtained by cross-linked by electron beam in the presence of triallylcyanurate (TAC).}

Chlorinated polyethylene (CPE) is a synthetic elastomer produced by the means of controlled chlorination of polyethylene and has been commercially produced since the late 1960s (Stelescu et al., 2011; Stelescu et al., 2008; U.S. Patent, 1969). A generalized chemical structure for CPE is shown in Figure 11.

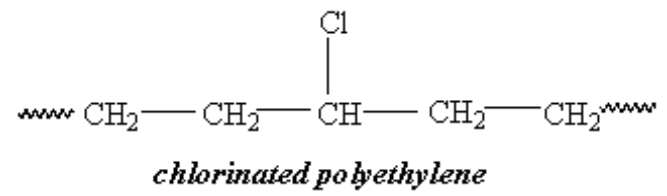

Figure 11. Chemical structure of chlorinated polyethylene (CPE).

Chlorinated Polyethylene Elastomers (CPE) are produced from HDPE that is randomly chlorinated in an aqueous slurry. Polymers are differentiated by chlorine content, molecular weight and crystallinity. Chlorine contents generally range from 25 to $42 \%$. Advantages in using CPE, include very good resistance to ozone, oxidation, abrasion and flex cracking. CPE also has good resistance to alcohols, alkalis and acids. Limitations for CPE include moderate resistance to aromatic oxygenated solvents (Hallstar, 2009) Cure agents for CPE compounds are typically based on (1) peroxide cure systems with coagents; (2) thiadiazolebased chemistries; or (3) irradiation crosslinking techniques (Stelescu et al., 2011; Stelescu et al., 2008). The choice of cure system depends upon a number of factors such as compound cost, processing equipment and curing equipment. Peroxide cures are preferred when extra scorch safety, shelf life, bin stability, low permanent set and high-temperature performance are desired. Irradiation-curable compounds are usually formulated in a manner similar to the peroxide-curable compounds, except that no peroxide is necessary (Stelescu et al., 2011; Flynn et al., 1985). About $70 \%$ of CPE is used in wire and cable applications with trimellitates the plasticizer of choice. The remaining applications, each at $15 \%$, are hydraulic hose and molded/extruded automotive parts (Hallstar, 2009).

In our experiments (Stelescu et al., 2008), we chose an efficient coagent for crosslinking of CPE by electron beam irradiation: triallyl cyanurate (TAC), to increase the rate and degree of 
cure. Materials used in the study: CPE TX10 chlorinated polyethylene (35\% chlorine), barium sulphate, titanium dioxide, calcium silicate, chlorinated paraffin, Uvinul 5050 antioxidant and TAC DL 70 trialylcyanided polyfunctional monomer; in the control blends the vulcanizing agent di(tert-buthylperoxiisopropyl) benzene (Perkadox 14-40B-GR) was used. Blends were prepared by mixing on a laboratory roller mill electrically heated up to $100-110^{\circ} \mathrm{C}$ for $10^{\prime}$. Ingredients were added in the following sequence: $\mathrm{CPE}$, titanium dioxide after CPE was adhered to the roller, calcium silicate and the antioxidant, barium sulphate and chlorinated paraffin, and finally the polyfunctional TAC monomer. To the control blends 8 phr Perkadox was added after the blend preparation. Blends were homogenized on the laboratory roller mill, and from these plates were obtained by pressing in an hydraulic press. The resulting plates were packed in a polyethylene film and subjected to 5, 1015 and 20 Mrad irradiation in the ILU-6M electron bem accelerator.

The crosslinking and grafting of $\mathrm{CPE}$ blends by accelerated electron radiation was proved by comparing physical-mechanical characteristics of the irradiated blends with those of the control blends with the same composition but crosslinked by classical method with peroxides. Physical-mechanical characteristics for the blends of CPE TX10 chlorinated polyethylene containing barium sulphate, titanium dioxide, calcium silicate, chlorinated paraffin, Uvinul 5050 and TAC, irradiated with different doses of accelerated electrons are shown in Figures 12-17. Hardness has shown higher values than that of the non-irradiated blend (63hA ), and a slight decrease with the increase in the TAC amount (Figure 12); increasing further the EB dose above $5 \mathrm{Mrad}$ has resulted in no improvement of this characteristic. The control blends have shown an increase of the hardness from 69 'ShA up to $76{ }^{\circ} \mathrm{ShA}$ with the increase in the TAC amount. The resulting values for these are comparable with the values obtained by irradiation.

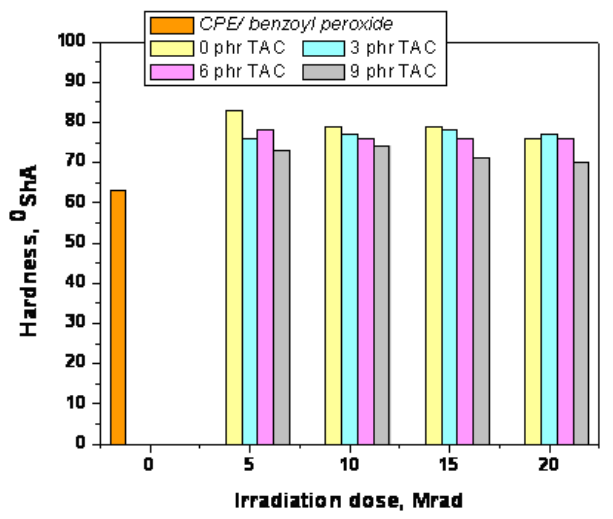

Figure 12. Changes in hardness versus the irradiation dose and TAC percentage. 


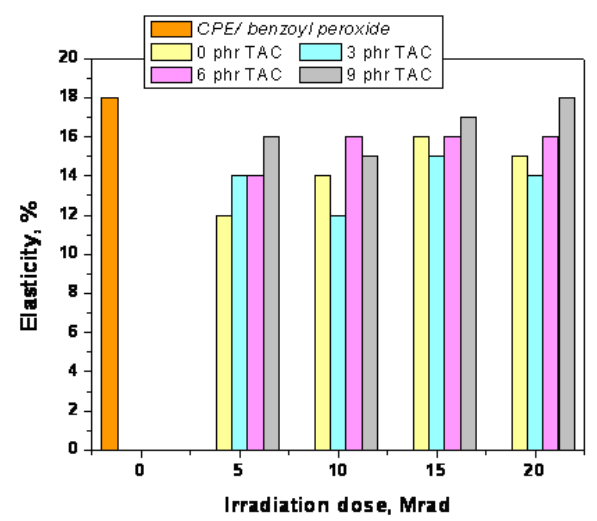

Figure 13. Changes elasticity versus the irradiation dose and TMPT percentage

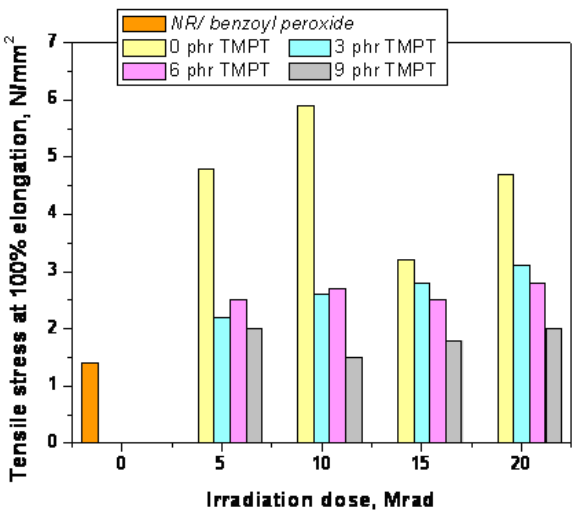

Figure 14. Changes in tensile stress at $100 \%$ elongation versus the irradiation dose and TMPT percentage

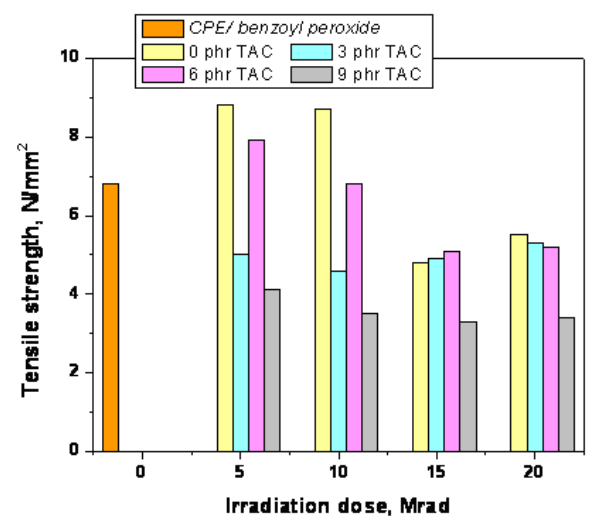

Figure 15. Changes in tensile strength versus the irradiation dose and TMPT percentage 


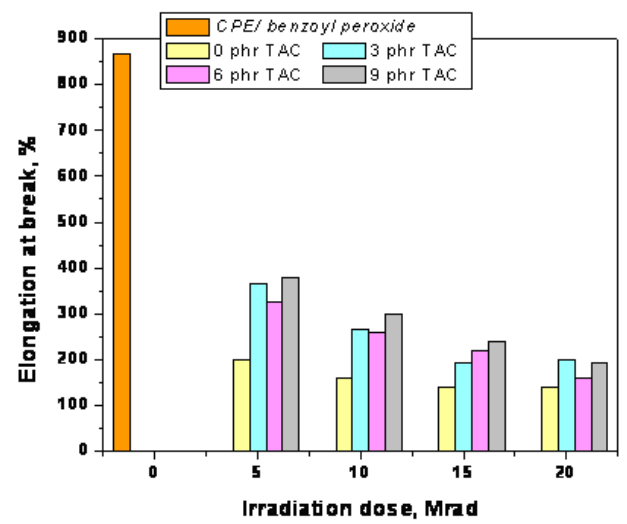

Figure 16. Changes in elongation at break versus the irradiation dose and TMPT percentage

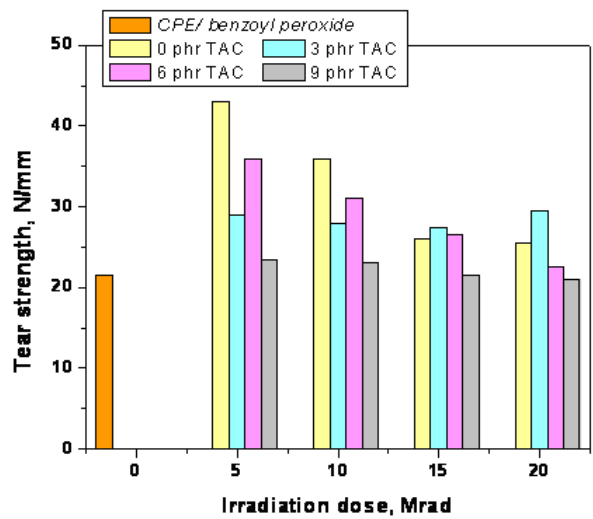

Figure 17. Changes in tear strength versus the irradiation dose and TMPT percentage

Elasticity (Figure 13) has shown a decrease when irradiating the sample with 5 Mrad and thereafter has increased with the in increase in the AE dose. Elasticity has increased as the TAC amount was increased. The elasticity in controls (crosslinked with Percadox) has decreased (from $18 \%$ down to $15 \%$ ) as the TAC amount was increased. Tensile stress at $100 \%$ elongation has shown a decrease as the TAC amount was increased and has shown higher values than those for the non-irradiated blend for all irradiation doses (Figure 14); in controls the tensile stress at $100 \%$ elongation has shown increased values (from $1.6 \mathrm{~N} / \mathrm{mm}^{2}$ up to $3 \mathrm{~N} / \mathrm{mm}^{2}$ ) as the TAC amount was increased. Tensile strength (figure 15) has shown a decrease as the as the irradiation dose was increased from $5 \mathrm{Mrad}$ up to $15 \mathrm{Mrad}$, and thereafter a slight increase revealed for all the TAC amounts; it has shown values comparable with those for the samples crosslinked with peroxides; Elongation at break have decreased as the irradiation dose and the TAC amount were increased, the resulting values being lower than those for the non-irradiated blend (Figures 16); the variation of this characteristic has revealed the CPE crosslinking with an irradiation dose as low as 5 Mrad. 
The control blends have shown a decrease in the elongation at break (from $50 \%$ down to 260 $\%)$ as the TAC amount was increased. Tear strength (Figure 17) has increased at irradiation doses of $5 \mathrm{Mrad}$, and thereafter has decreased as the EB irradiation dose was increased. Tear strength has shown a non-uniform variation as the TAC amount was increased. In controls the tear strength has increased as the TAC amount was increased from $29.5 \mathrm{~N} / \mathrm{mm}$ up to 38 $\mathrm{N} / \mathrm{mm}$.

The rheological characteristics of the controls obtained measured by the Monsanto rheometer are shown in table 12 .

\begin{tabular}{|c|c|c|c|c|}
\hline Characteristic & 0 phr TAC & 3 phr TAC & 6 phr TAC & 9 phr TAC \\
\hline $\mathrm{T}_{\min }$ & $1^{\prime} 30$ & $1^{\prime} 30$ & $1^{\prime} 15$ & $1^{\prime} 15$ \\
\hline $\mathrm{T}_{2}$ & $2^{\prime} 30$ & $3^{\prime}$ & $22^{\prime} 15$ & $2^{\prime} 15$ \\
\hline $\mathrm{M}_{\min }(\mathrm{dN} / \mathrm{m})$ & 10 & 7.5 & 6.4 & 7.5 \\
\hline $\mathrm{M}_{\max }(\mathrm{dN} / \mathrm{m})$ & 33.2 & 36.2 & 47 & 45 \\
\hline $\mathrm{M}_{90}$ & 30.88 & 33.33 & 42.94 & 41.25 \\
\hline $\mathrm{T}_{90}, \min$ & $9^{\prime} 15^{\prime \prime}$ & $7^{\prime} 15^{\prime \prime}$ & $7^{\prime}$ & $10^{\prime}$ \\
\hline $\mathrm{I}_{\mathrm{vv}}$ & 14.81 & 23.53 & 21.05 & 12.9 \\
\hline $\mathrm{V}_{2 \mathrm{c}}$ & 0.814 & 0.830 & 0.851 & 0.847 \\
\hline
\end{tabular}

Table 12. Rheological characteristics of CPE blends cross-linked with peroxides

The above data have revealed the following features with the increase in the amount of polyfunctional TAC monomer: the minimum moment of shearing has decreased, and the maximum moment of shearing has increased up to a TAC amount of 6 phr; the best vulcanization time has shown a minimum at $6 \mathrm{phr}$ TAC and thereafter has increased. The index of vulcanization rate has increased by $59 \%$ at 3 phr TAC, then has decreased slightly (by $10 \%$ ) when the amount of TAC was increased up to $6 \mathrm{phr}$, and has decreased significantly when the amount of TAC was increased further up to $9 \mathrm{phr}$. The highest value (by $4.5 \%$ higher than that for a blend free TAC) of the vulcanization factor was found for 6 phr TAC, and it has decreased (by $0.5 \%$ ) as the TAC amount was increased up to 9 phr.

The best physical-mechanical characteristics were obtained by adding $0-6$ phr TAC to the blends and applying an irradiation dose of $5 \mathrm{Mrad}$. When comparing the best vulcanization time ( $\left.\mathrm{T}_{90}\right)$ with the time required with an irradiation of $5 \mathrm{Mrad}$, it has shown a decrease of 2.8 times in crosslinking by irradiation that has resulted in a shorter time required to obtain CPE-based finished products. In addition, the irradiation process is in continuous flow.

\subsection{Characteristics of ethylene-propylene rubber (EPDM) obtained by cross- linked with electron beam and microwave in the presence of trimethylopropane trimethacrylate (TMPT)}

Ethylene-propylene rubbers use the same chemical building blocks or monomers as polyethylene (PE) and polypropylene (PP) thermoplastic polymers. These ethylene (C2) and propylene $(\mathrm{C} 3)$ monomers are combined in a random manner to produce rubbery and stable 
polymers. A wide family of ethylene-propylene elastomers can be produced ranging from amorphous, non-crystalline to semi-crystalline structures depending on polymer composition and how the monomers are combined (Karpeles \& Grossi, 2001). These polymers are also produced in an exceptionally wide range of Mooney viscosities (or molecular weights). The ethylene and propylene monomers combine to form a chemically saturated, stable polymer backbone providing excellent heat, oxidation, ozone and weather aging. A third, non-conjugated diene monomer can be terpolymerized in a controlled manner to maintain a saturated backbone and place the reactive unsaturation in a side chain available for vulcanization or polymer modification chemistry. The terpolymers are referred to as EPDM (or ethylene-propylene-diene with " $\mathrm{M}$ " referring to the saturated backbone structure). An EPDM polymer structure is illustrated in Figure 18. The ethylene-propylene copolymers are called EPM.

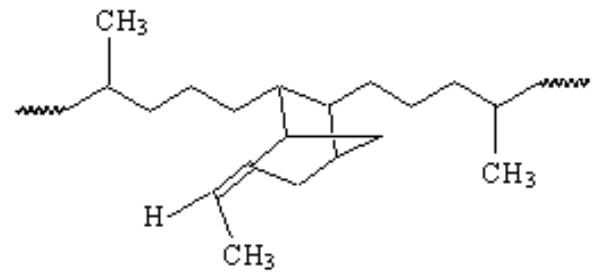

ethylene-propilene elastomers

Figure 18. Chemical structure of ethylene-propylene terpolymer (EPDM)

The most important stage in the EPDM rubber processing technology is vulcanization / crosslinking by sulphur and accelerator or by peroxides. Radiation vulcanization is applicable, but the dose required for EPDM vulcanization is very high (Odian, 1964). To reduce the dose for vulcanization of EPDM, some researches have worked on the introduction of coagents/polyfunctional monomers such as ethylene glycol dimethacrylate, triallyl cyanurate, triallyl isocyanurate, trimethylolpropane trimethacrylate etc (Manaila, Stelescu, Ighigeanu et al., 2011)

The following materials were used in the study: EPDM rubber (Nordel 4760); trimethylopropane-trimethacrylate Luvomaxx TMPT DL 75; dibenzoyl peroxide Perkadox 14-40B for he control blends (Manaila, Stelescu, Ighigeanu et al., 2011).

Blends were prepared on an electrically heated laboratory roller mill. For preparation of EPDM with polyfunctional monomer TMPT, the blend constituents were added in the following sequence and amounts: $100 \mathrm{phr}$ EPDM and $3 \mathrm{phr}$ TMPT. Process variables: temperature $75 \pm 5^{\circ} \mathrm{C}$, friction $1: 1.1$, and total blending time $5 \mathrm{~min}$. Plates required for physical-mechanical tests were obtained by pressing in a hydraulic press at $120 \pm 5^{\circ} \mathrm{C}$ and $150 \mathrm{MPa}$. Dibenzoyl peroxide vulcanized samples were prepared similarly to the experimental ones with the following specifications: $8 \mathrm{phr}$ of dibenzoyl peroxide as vulcanizing agent was added and the blend vulcanization was achieved in a hydraulic press at $160^{\circ} \mathrm{C}$; the optimum vulcanization time was measured by means of Monsanto Rheometer. The resulted plates were treated by irradiation, using the accelerator ALIN-10. 
In Table 13 are presented characteristics of the mixtures cross-linked with dibenzoyl peroxide. These, along with non-irradiated and non-crosslinked samples are considered control samples for mixtures cross-linked by irradiation with EA or EA and microwave.

\begin{tabular}{|l|c|}
\hline Rheologic characteristics & EPDM+TMPT+ dibenzoyl peroxide \\
\hline T90 (minutes) & $23^{\prime} 30^{\prime \prime}$ \\
\hline $\mathrm{M}_{\min }(\mathrm{dNm})$ & 1 \\
\hline $\mathrm{M}$ max $(\mathrm{dNm})$ & 46.8 \\
\hline$\Delta \mathrm{M}(\mathrm{dNm})$ & 31.6 \\
\hline $\mathrm{M} 90(\mathrm{dNm})$ & 42.64 \\
\hline T90 $($ minutes) & $6^{\prime} 45^{\prime \prime}$ \\
\hline Physical-mechanical characteristics & \\
\hline Hardness, ${ }^{\circ}$ ShA & 64 \\
\hline Elasticity, $\%$ & 60 \\
\hline Tensile strength, N/mm ${ }^{2}$ & 2.1 \\
\hline Elongation at break, \% & 127 \\
\hline Permanent set, $\%$ & 5 \\
\hline Tear strength, N/mm & 13.5 \\
\hline
\end{tabular}

Table 13. Rheological characteristics of EPDM/TMPT blends cross-linked with peroxides

The mechanical properties of samples are summarized in Figures 19-26. The hardness

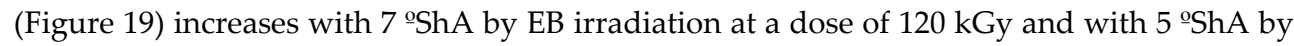
$\mathrm{EB}+\mathrm{MW}$ irradiation at $30 \mathrm{kGy}+83 \mathrm{~s}$ and $60 \mathrm{kGy}+176 \mathrm{~s}$. For the other treatments, hardness change insignificantly - with 1-2 ${ }^{\circ} \mathrm{ShA}$; also, there is no big difference between the EB and EB + MW crosslinking. Analyzing the irradiated samples (with EB or EB+MW) and the control sample crosslinked with peroxide (see Table 13), can be noticed that there are no significant differences. The hardness increasing of samples crosslinked by irradiation or by curing with peroxide comparing with non-crosslinked sample is due to the reinforcing effect that occurs as a result of the formation of crosslinking bridges. The elasticity (Figure 20) does not change significantly by irradiation with EB or EB + MW (an increase of only $2 \%$ ). There is a growing of elasticity with maximum $1 \%$ for EB + MW compared with EB only, for the treatment of $30 \mathrm{kGy}+88 \mathrm{~s}$. The same increase in elasticity was observed in the case of crosslinked with peroxide. The tensile stress at 100\% elongation (Figure 21) and tensile stress at $300 \%$ elongation (Figure 22) increase by irradiation, but the obtained values are small because the material is not with filler.

There are little differences between values obtained by peroxide, EB and EB + MW crosslinking. Considering the fact that the tensile stress at $100 \%$ elongation is a measure of the crosslinking degree, the values obtained show that by samples irradiation takes place the increasing of the crosslinking degree (Yasin et al., 2005). 


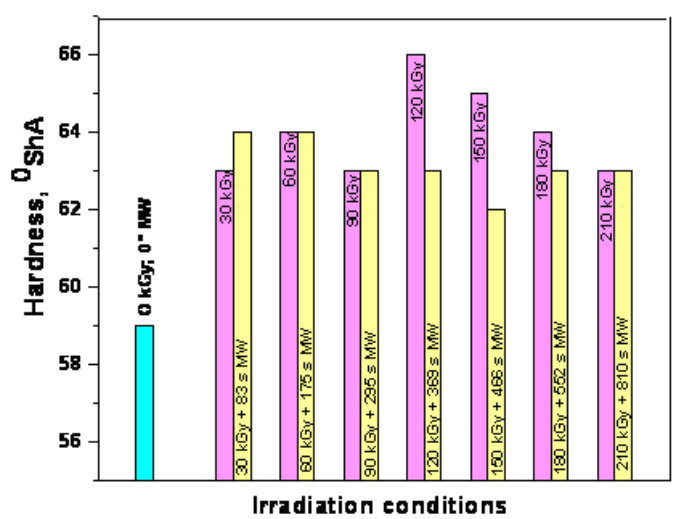

Figure 19. The EB and EB+MW effects on the hardness of the EPDM samples

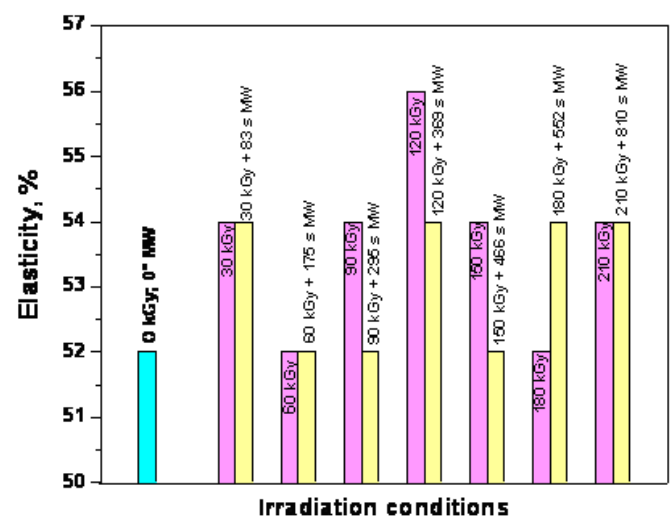

Figure 20. The EB and EB+MW effects on the elasticity of the EPDM samples

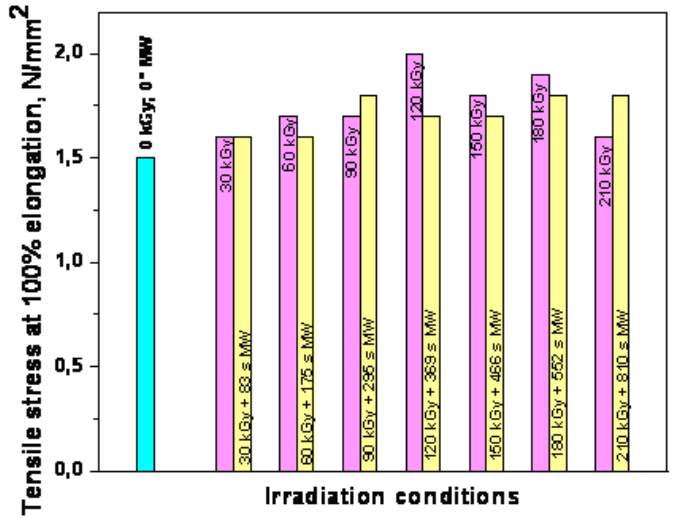

Figure 21. The EB and EB+MW effects on the tensile stress at $100 \%$ elongation of the EPDM samples 


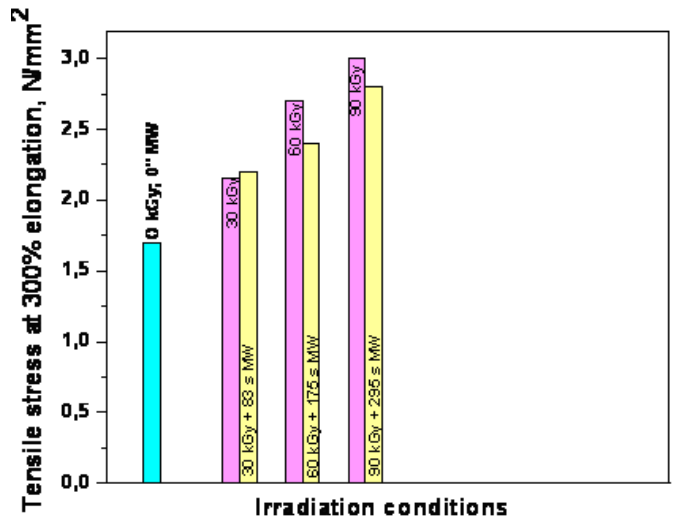

Figure 22. The EB and EB+MW effects on the tensile stress at 300\% elongation of the EPDM samples

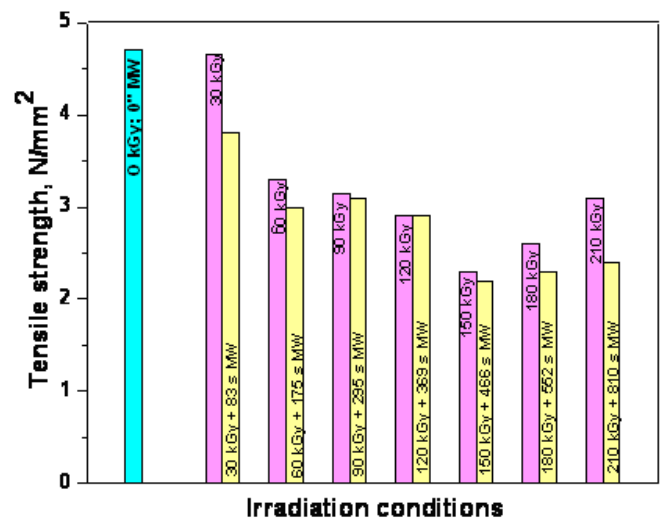

Figure 23. The EB and EB+MW effects on the tensile strength of the EPDM samples

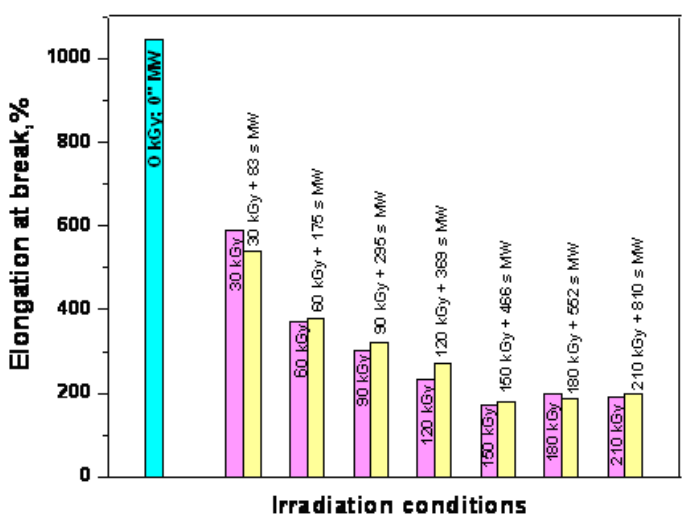

Figure 24. The EB and EB+MW effects on the elongation at break of the EPDM samples 


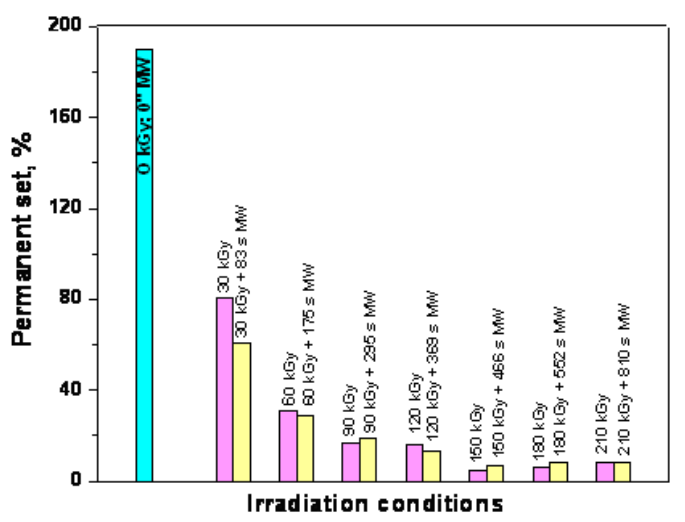

Figure 25. The EB and EB+MW effects on the permanent set of the EPDM samples

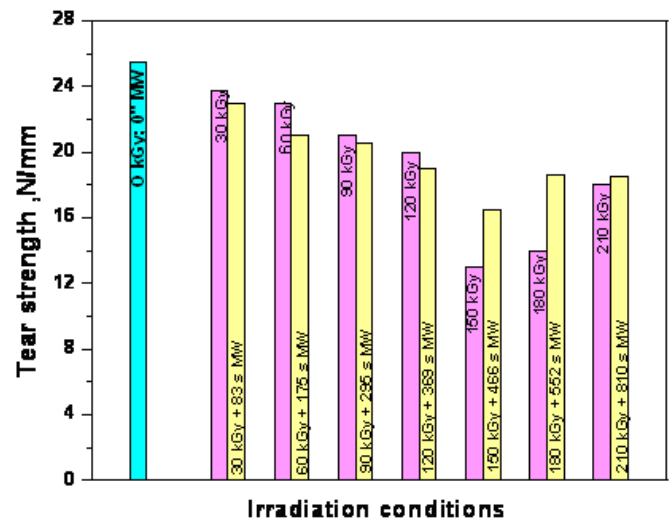

Figure 26. The EB and EB+MW effects on the tear strength of the EPDM samples

Tensile strength (Figure 23), elongation at break (Figure 24), permanent set (Figure 25) and tear strength (Figure 26) decrease with the irradiation dose increasing for both EB and EB + MW irradiation, (comparing with non-irradiated control sample), but the characteristics from crosslinking by irradiation are better compared with crosslinking with peroxide. For all these mechanical features the best results are obtained for a dose of $150 \mathrm{kGy}$ (crosslinking with EB) and $150 \mathrm{kGy}+466 \mathrm{~s}$ (crosslinking wit EB + MW). Following the obtained results it can be stated that a dose of maximum $150 \mathrm{kGy}+466 \mathrm{~s}$. leads to a good degree of crosslinking, for which there is a return to its original shape after a very good stretching $(29 \%)$.

\section{Conclusion}

This review gives an overview about our research on elastomer crosslinking by irradiation with accelerated electrons, a much more ecologic method that does not need to add crosslinking agents into the blend. Crosslinking by EB and EB+MW also shows a series of 
advantages, like as: reduced crosslinking time, no polymer degradation due to high temperature (as in the classic peroxide curing) because EB and EB+MW crosslinking is performed at room temperature, the process is very fast and can be controlled precisely. At the interaction of ionizing radiation with (co)polymers, breaking of covalent bonds occurs, as well as the emergence of free radicals (transitional chemical species) on the main chain (if the lateral groups break) or in the main chain (if it breaks itself). The final effect is either crosslinking of macromolecular assembly or cutting the main chain of macromolecules and decreasing average molecular weight. In fact, the two effects, crosslinking and degradation, coexist and we need to point out the predominance of one of them. In addition, through appropriate surface treatments, some features of the feet such as appearance, adhesion to different materials or slip resistance can be significantly improved (Zaharescu, 2000).

\section{Author details}

Elena Manaila, Maria Daniela Stelescu* and Gabriela Craciun

National Research and Development Institute for Laser,

Plasma and Radiation Physics, Magurele, Bucharest, Romania

Maria Daniela Stelescu

National Research and Development Institute for Textiles and

Leather - Leather and Footwear Research Institute, Bucharest, Romania

\section{References}

Alvarez Grima, M.M. (2007). Novel Co-agents for Improved Properties in Peroxide Cure of Saturated Elastomers, PhD Thesis, Printed by Print Partners Ipskamp, ISBN: 90-365-24563, Enschede, Netherlands

Andreo, P., Cunningham, J.F., Hohlfeld, K., \&. Svensson, H. (1997). Absorbed dose determination in photon and electron beams : An International code of practice, Technical Reports Series No.277, $2^{\text {nd }}$ edition, International Atomic Energy Agency, Vienna

Bhowmick, A. K. \& Vijayabaskar, V. (2006). Electron beam curing of elastomer, Rubber Chemistry and Technology, Vol.79, No.3, pp. 402-428

Boye, W.M. (2008). Utilizing Coagents in the Electron Beam Cure of Elastomers, Proceedings of the 57th International Wire \& Cable Symposium IWCS, pp.335- 341

Chowdhury, R. \& Banerji, M.S. (2005). Electron Beam Irradiation of Ethylene-propylene Terpolymer: Evaluation of Trimethylol Propane Trimethacrylate as a Crosslink Promoter, Journal of Applied Polymer Science, Vol.97, No.3, pp. 968-975

Chlorinated polyethylene; CM (CPE). (2009). pp. 23-25, www.hallstar.com;

Dikland, H. G., Ruardy, T., Van der Does, L. \& Bantjes, A. (1993). New coagents in peroxide vulcanization of EPM, Rubber Chemistry and Technology, Vol.66, No.5, pp.693-711

Dluzneski, P.R. (2001). Peroxide vulcanization of elastomers, Rubber Chemistry and Technology, Vol.74, No.3, pp. 451-492

\footnotetext{
* Corresponding Author
} 
Endstra, W.C. (1990). Application of coagents for peroxide crosslinking, Kautschuk und Gummi Kunststoffe, Vol.43, No.9, pp.790-793

Flynn, J. H. \& Davis, W. H. (1985). Tyriny Brand CPE Thiadiazole Cure System StudiesChemistry and Dispersion, presented at a meeting of the Rubber Division, American Chemical Society, Los Angeles, California, 23-26 April 1985.

Hafezi, M., Khorasani, S.N. \& Ziaei, F. (2006). Application of Taguchi method in determining optimum level of curing system of NBR/PVC blend, Journal of Applied Polymer Science, Vol.102, No.6, pp.5358-5362

Henning, S.K. (2008). The Use of Coagents in the Radical Cure of Elastomers, Proceedings of the 56 th International Wire \& Cable Symposium, pp. 587-593

Henning, S.K. (2008). Use of coagents in the radical cure of elastomers, , Wire $\mathcal{E}$ Cable Technology International, Vol. XXXVI, No. 3, pp.52-59

Hofmann, H. (1967). Vulcanization and vulcanizing agents, MacLaren and Sons Ltd, London, Palmerton Publishing Co. Inc., New York.

Karpeles, R. \& Grossi, A.G. (2001). EPDM Rubber Technology, Handbook of Elastomers, $2^{\text {nd }}$ Ed., Anil K. Bhowmick and Howard L. Stephens [Editors], Marcel Decker, Inc., New York, pp. 845-876.

Manaila, E., Martin, D., Zuga, D., Craciun, G., Ighigeanu, D. \& Matei, C. (2008). Radiation processing of rubber mixtures with polyfunctional monomers, Proceedings of the 11th International Conference on Optimization of Electrical and Electronic Equipment, OPTIM, Vol.1, pp. 125-130, Brasov, Romania, 22-23 May 2008

Manaila, E., Martin, D., Stelescu, M.D, Craciun, g., Ighigeanu, D. \& Matei, C. (2009). Combined effects of microwaves, electron beams and polyfunctional monomers on rubber vulcanization, Journal of Microwave Power and Electromagnetic Energy (JMPEE), Vol.43, No.3, pp.26-34

Manaila, E., Martin, D., Craciun, G., Zuga, D. \& Ighigeanu, D. (2009). Electron beam processing of rubber mixtures with polyfunctional monomers, Proceedings of the $7^{\text {th }}$ Conference on Nuclear and Particle Physics (NUPPAC'09), pp.645-650, Sharm El-Sheikh, Egypt, 11-15 Nov. 2009

Manaila, E., Stelescu, M.D., Ighigeanu. D, Craciun, D. \& Berechet, D. (2011), The influence of TMPT coagent on the mechanical properties of the EPDM rubber cross-linked by irradiation Leather and Footwear Journal, Vol.11, No.3, pp.201-210

Manaila, E., Stelescu, M.D. \& Craciun, G. (2011). Characteristics of natural rubber blends vulcanized with electron beam and microwave, Leather and Footwear Journal, Vol.11, No.1, pp. 43-52.

Martin, D., Jianu, A. \& Ighigeanu, D. (2001). A method for the 2.45-GHz magnetron output power control, Transactions on Microwave Theory and Techniques IEEE, Vol.49, No.3 (2001) 542.

Martin, D., Ighigeanu, D., Mateescu, E., Craciun, G. \& Ighigeanu, A. (2002). Vulcanization of rubber mixtures by simultaneous electron beam and microwave irradiation, Radiation Physics and Chemistry, Vol.65, No.1, pp. 63-65

MGM Rubber Company-Research and Development, (2007). Electron Beam Radiation Technology for Curing, http://www.mgmrc.com/ebeam-trech.htm 
Odian, G. (1964). Radiation crosslinking of polyethylene-polyfunctional monomer mixtures, Journal of Polymer Science, Vol.2, No.6, pp.2835-2848

Stelescu, M.D, Manaila, E. \& Zuga, N. (2011). The use of polyfunctional monomers in the radical cure of chlorinated polyethylene, Polymer Journal, Vol.43, No.9, pp.792-800

Stelescu, M.D., Manaila, E., Craciun, G. \& Zuga, N. (2012). Crosslinking and grafting ethylene vinyl acetate copolymer with accelerated electrons in the presence of polyfunctional monomers, Polymer Bulletin, Vol. 68, No.1, pp.263-285.

Stelescu, M.D. \& Manaila, E. (2007), Crosslinking and grafting the natural rubber by means of accelerated electrons in the presence of trimethylol-propane trimethacrylate (TMPT), Scientific Bulletin, B Series: Chemistry and Materials Science, Vol.69, No.4, pp.33-38

Stelescu, M.D., Georgescu, M. \& Manaila, E. (2010). Aspects regarding crosslinking of a natural rubber blend, Proceedings of the $3^{\text {rd }}$ International Conference Advanced Materials and Systems, ICAMS 2010, pp. 313-318, Bucharest, Romania, 16-18 September 2010

Stelescu, M.D., Niculescu-Aron, I.G. \& Manaila, E. (2009). Processing and statistical analysis of the experimental data resulted from EPDM rubber grafting and crosslinking with accelerated electrons in the presence of TMPT, Materiale plastice, Vol.46, No.1, pp.48-52

Stelescu, M.D., Vaslan, M. \& Manaila, E. (2008). Materials based on chlorinates polyethylene obtained by crosslinking and grafting by accelerated electrons in the presence of trialylcyanurated, Proceedings of the $2^{\text {rd }}$ International Conference Advanced Materials and Systems, ICAMS 2008, pp. 96-101, Bucharest, Romania, 23-24 October 2008

U.S. Patent 3454 544, Process for the Chlorination of Polyolefins, Issued 8 July 1969 to Dow Chemical USA.

Van Duin, M. (2002). Chemistry of EPDM Crosslinking, Kautschuk und Gummi, Kunststoffe,Vol.55, No.4, pp.150-156

Vijayabaskar, V. \& Bhowmick, A. K. (2005). Electron beam modification of nitrile rubber in the presence of polyfunctional monomer, Journal of Applied Polymer Science, Vol. 95, No.2, pp. 435-447

Yasin, T., Ahmed, S., Ahmed, M. \& Yoshii, F. (2005). Effect of concentration of polyfunctional monomers on physical properties of acrylonitrile-butadiene rubber under-electron beam irradiation, Radiation Physics and Chemistry, Vol.73, No.3, pp. 155158

Zaharescu, T., Setnescu, R., Jipa, S. \& Setnescu, T. (2000). Radiation processing of polyolefin blends. I. Crosslinking of EPDM-PP blends, Journal of Applied Polymer Science, Vol. 77, No.5, pp. 982-987

Zuga, M.D., Iovu, H., Trandafir, V., Manaila, E., Martin., D. \& Stelescu, M.M. (2007). Study on the preparation of some biocomposites based on silicone elastomers and collagen, Jurnal of Optoelectronics and Advenced Materials (JOAM), Vol.9, No.11, pp.3325-3329

Zuga, M.D., Miu., L., Crudu, M., Bratulescu, V., Iovu, H. \& Manaila, E. (2007). Products of ethylene-propylene-terpolymer rubber (EPDM) obtained by an environmentally friendly process, Advanced Materials Research - Materials and Technologies, Vol.23, pp. 333-336 